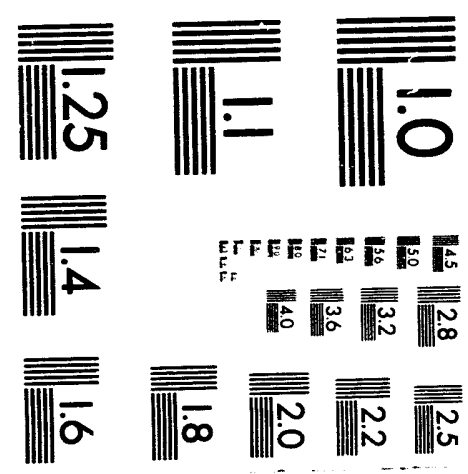



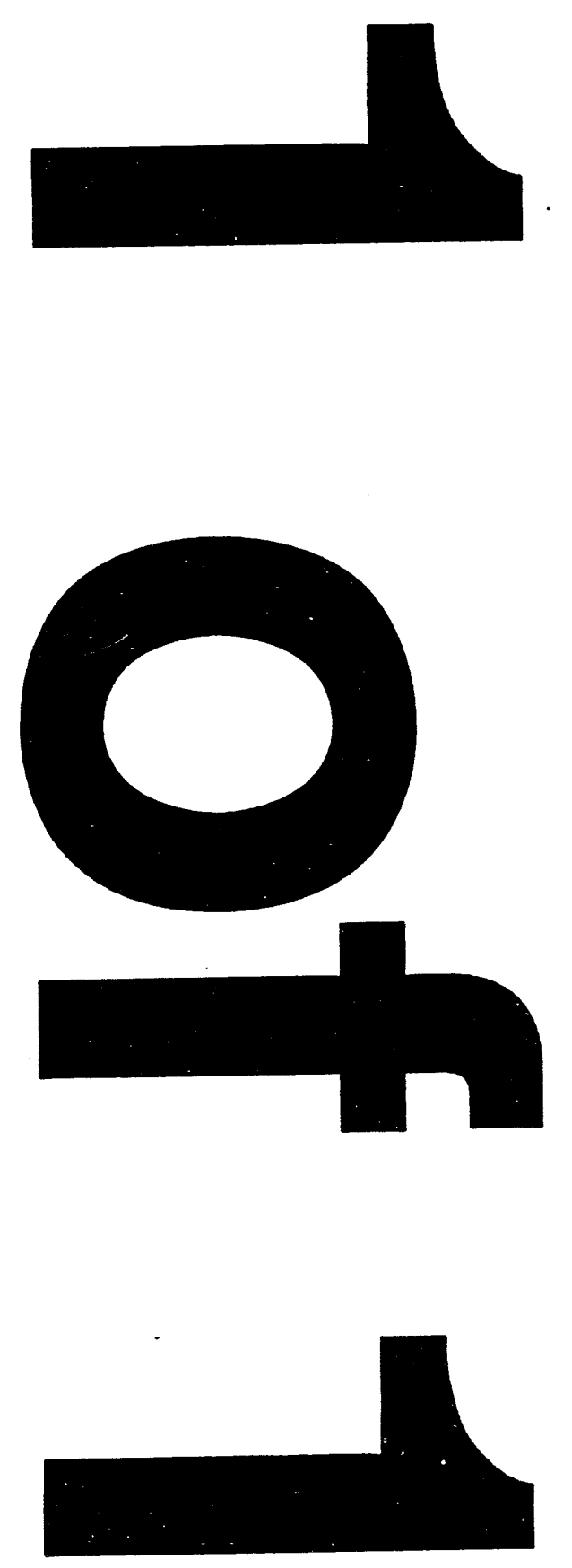


\title{
NUCLEAR CRITICALITY SAFETY EVALUATION OF SPRAY BOOTH OPERATIONS IN X-705, PORTSMOUTH GASEOUS DIFFUSION PLANT
}

\author{
M. K. Sheaffer \\ S. C. Keeton
}

September 20, 1993

This is an informal report intended primarily for internal or limited external distribution. The opinions and conclusions stated are those of the author and may or may not be those of the Laboratory.

Work performed under the auspices of the U.S. Department of Energy by the Lawrence Livermore National Laboratory under Contract W-7405-Eng-48.

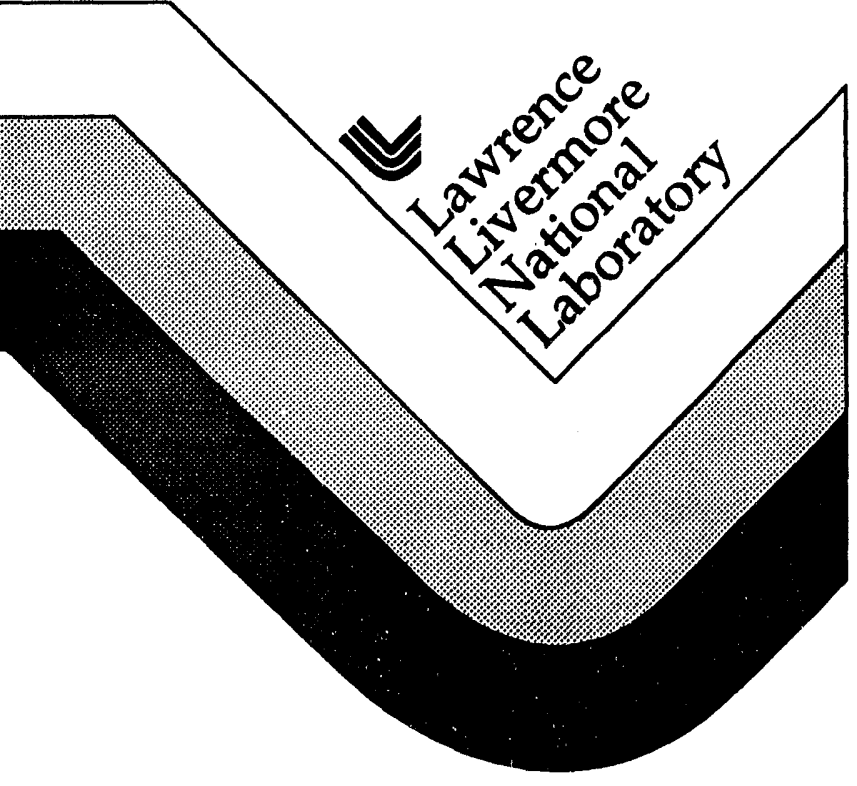




\section{DISCLAIMER}

This document was prepared as an account of work sponsored by an agency of the United States Government. Neither the United States Government nor the University of Califomia nor any of their employees, malkes any warranty, express or implied, or sssumes any legal liability or reaponsibility for the accuracy, completeness, or usefulness of any information, apparatus, product, or process disclosed, or represents that its use would not infringe privately owned rights. Reference herein to eny specific commercial products, process, or service by trade name, trademark, manufacturer, or otherwise, does not necessarily constitute or imply its endorsement, recommendation, or favoring by the United States Government or the University of California. The views and opinions of authors expressed herein do not necessarily state or reflect those of the United States Government or the University of California, and shall not be used for advertising or product endorsement purposes.

This report has been reproduced

directly from the best available copy.

Available to DOE and DOE contractors from the Orfice of Scientific and Technical Information

P.O. Box 62, Oak Ridge, TN 37831

Prices available from (615) 576-8401, FTS 626-8401

Available to the public from the

National Technical Information Service

U.S. Department of Commerce

5285 Port Royal Rd.

Springlield, VA 22161 


\section{Nuclear criticality safety evaluation of Spray Booth Operations in X-705, Portsmouth Gaseous Diffusion Plant}

20 Sep 1993

Lawrence Livermore National Lab., CA (United States)

Reproduced and Distributed by:

U.S. DEPARTMENT OF ENERGY

Office of Scientific and Technical Information

P.O. Box 62

Oak Ridge, TN 37831 


\section{ACKNOWLEDGMENTS}

We would like to thank the numerous PORTS personnel who assisted in the collection of information for this report and who took time from their busy schedules to acquaint us with the operations in $X-705$. This report would not have been possible without the cooperation of Rob Oxenham and Donna D'Aquila of the PORTS NCS Department.

Specific recognition should also be given to the X-705 staff. Melody Channel's support of our administrative and logistical requirements was truly outstanding. Dave Dalton, Bob Stanley, Rudy Spaeth, Jeff Woodard, Mark Parker, and Kevin Clausing played a significant role in explaining Spray Booth Operations and in providing additional details not apparent from existing documentation.

Finally, we wish to acknowledge the support we received from the MMES staff at Oak Ridge, particularly Tom Lemons, Curtis Jordan, and Howard Dyer. 


\section{TABLE OF CONTENTS}

\section{Page}

ACRONYMS iv

ABSTRACT

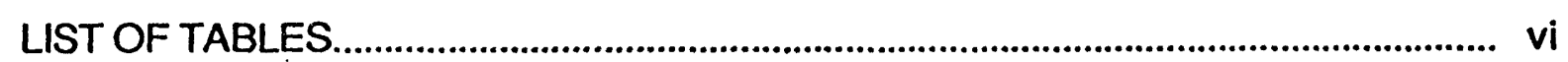

LIST OF FIGURES.................................................................................................... vii

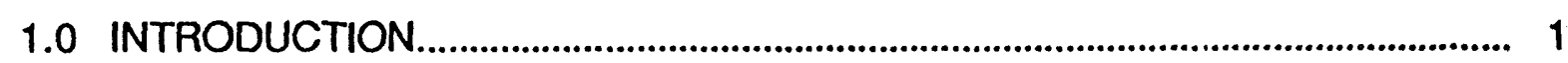

2.0 SUMMARY CONCLUSIONS.......................................................................... 4

3.0 DESCRIPTION OF SPRAY BOOTH OPERATIONS......................................... 6

3.1 Procedures and Equipment..................................................................... 6

3.2 Input and Output Streams of Fissile Material.......................................... 9

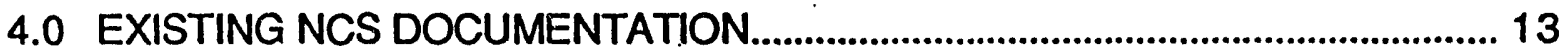

4.1 Final Safety Analysis Report (FSAR) ................................................. 13

4.2 Development Memos (DMs)............................................................. 13

4.3 Facility Change Agreements (FCAs)..................................................... 14

4.4 Operational Safety Requirements (OSRs) ..............................................15

4.5 Operating Methods (OMs) and Procedures......................................... 16

4.6 Engineering Drawings.................................................................................... 20

5.0 CONTROL PARAMETERS, ADMINISTRATIVE CONTROLS, AND

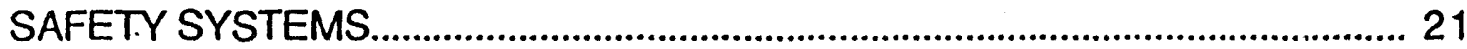

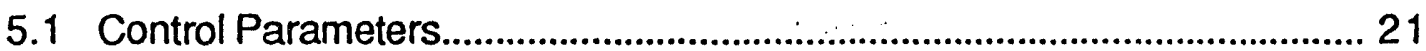

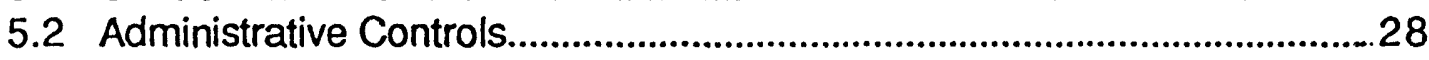

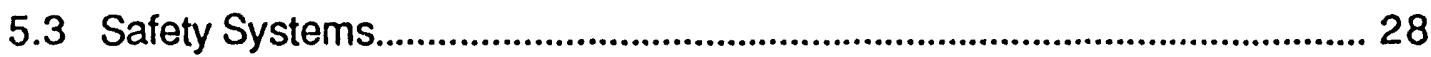

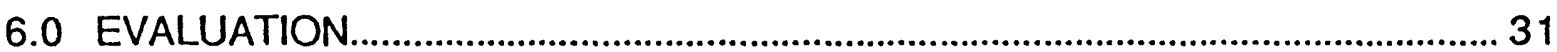

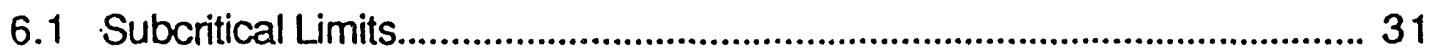

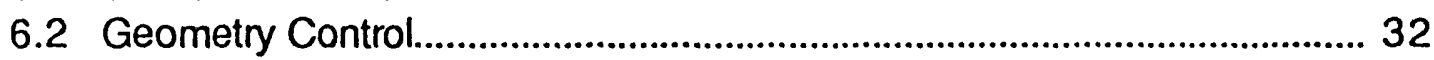

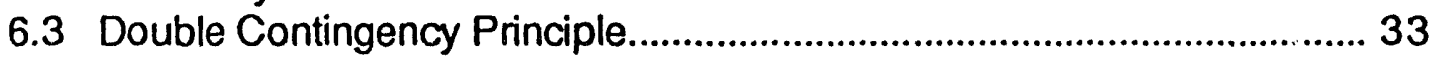

6.4 Outdated Documentation............................................................................. 36 
7.0 RECOMMENDATIONS. 37

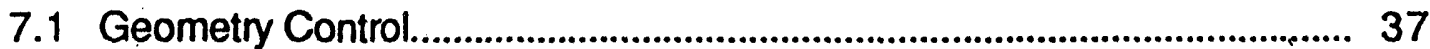

7.2 Double Contingency Principle.......................................................... 37

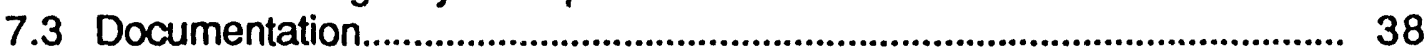

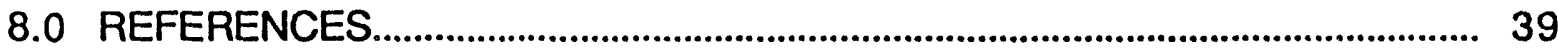

APPENDIX A - EXISTING NCS DOCUMENTATION........................................... A-1

APPENDIX B - CRITICALITY CALCULATIONS FOR THE SPRAY BOOTH PUMPS................................................................................. B-1

APPENDIX C - CRITICALITY CALCULATIONS FOR THE SCAVENGER PUMP C-1

APPENDIX D - CRITICALITY CALCULATIONS FOR THE ACID STORAGE COLUMNS. D-1 


\section{ACRONYMS}

$\begin{array}{lll}\text { ANSI } & - & \text { American National Standards Institute } \\ \text { ANS } & - & \text { American Nuclear Society } \\ \text { ANT } & - & \text { Applied Nuclear Technology } \\ \text { DOE } & - & \text { Department of Energy } \\ \text { DYMCAS } & - & \text { Dynamic Material Control Accounting System } \\ \text { ESR } & - & \text { Engineering Services Request } \\ \text { FA } & - & \text { Field Agreement } \\ \text { FCA } & - & \text { Facility Change Agreement } \\ \text { FSAR } & - & \text { Final Safety Analysis Report } \\ \text { GAT } & - & \text { Goodyear Atomic Corporation } \\ \text { GDP } & - & \text { Gaseous Diffusion Plant } \\ \text { HEU } & - & \text { Highly Enriched Uranium } \\ \text { IP } & - & \text { In-Hand Procedure (formerly OM) } \\ \text { LLNL } & - & \text { Lawrence Livermore National Laboratory } \\ \text { MSDS } & - & \text { Material Safety Data Sheet } \\ \text { MMES } & - & \text { Martin Marietta Energy Systems, Inc. } \\ \text { NCS } & - & \text { Nuclear Criticality Safety } \\ \text { NCSA } & - & \text { Nuclear Criticality Safety Approval } \\ \text { PEH } & - & \text { Planned Expeditious Handling } \\ \text { PGDP } & - & \text { Paducah Gaseous Diffusion Plant, Paducah, Kentucky } \\ \text { PORTS } & - & \text { Portsmouth Gaseous Diffusion Plant, Piketon, Ohio } \\ \text { OA } & - & \text { Operational Area } \\ \text { OGRU } & - & \text { Oil and Grease Removal Unit } \\ \text { OM } & - & \text { Operating Method } \\ \text { OSR } & - & \text { Operational Safety Requirement } \\ \text { RP } & - & \text { Reference Procedure } \\ \text { S } & - & \text { System } \\ \text { SS } & - & \text { Subsystem } \\ \text { UES } & - & \text { Uranium Enrichment Support } \\ & & \end{array}$




\section{ABSTRACT}

This report evaluates nuclear criticality safety for Spray Booth Operations in the Decontamination and Recovery Facility, X-705, at the Portsmouth Gaseous Diffusion Plant. A general description of current procedures and related hardware/equipment is presented. Control parameters relevant to nuclear criticality safety are explained, and a consolidated listing of administrative controls and safety systems is developed. Based on compliance with DOE Orders and MMES practices, the overall operation is evaluated, and recommendations for enhanced safety are suggested. 


\section{LIST OF TABLES}

\section{Page}

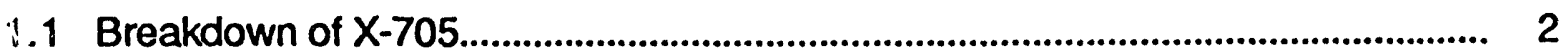

5.1 Administrative Controls for Spray Booth Operations...................................... 29

6.1 Subcritical Limits of ANSI/ANS 8.1 and GAT-225...................................... 31

B.1 Typical Input File for Results Shown in Figure B.2 ..................................... B-4

C.1 Typical Input File for Results Shown in Figure C.2 .....................................5

D.1 Typical Input File for Results Shown in Figure D.2 ..................................... D-5 


\section{LIST OF FIGURES}

Page

3.1 Schematic of X-705 spray booths................................................................... 7

3.2 Schematic of solution storage configuration in tunnel basement.................... 10

3.3 Schematic of input and output streams of fissile material............................... 12

5.1 Geometry under rinse booth floor grate............................................................... 22

B.1 Ladish Tri-Clover Model C218MD-256TC pump.............................................. B-2

B.2 $k_{\text {eff }}$ vs. uranium concentration for the Tri-Clover C218 pump........................... B-3

C.1 Wilden Model M8 pump......................................................................................... C-2

C.2 $\mathrm{k}_{\text {eff }}$ vs. uranium concentration for the Wilden M8 pump.................................. C-3

D.1 Schematic of 5-in. storage columns (top view) .............................................. D-2

D.2 Variation in $k_{\text {eff }}$ as a function of uranium concentration for.............................. D-3 full density paraffin

D.3 Variation in $\mathrm{k}_{\text {eff }}$ as a function of paraffin density for........................................ D-3 a uranium concentration of $800 \mathrm{~g} / \mathrm{l}$ 


\subsection{INTRODUCTION}

As part of its overall Uranium Enrichment Support (UES) Project, the Department of Energy (DOE) has tasked Lawrence Livermore National Laboratory to provide nuclear criticality safety (NCS) support to the gaseous diffusion plants (GDP). operated by Martin Marietta Energy Systems (MMES), near Portsmouth, Ohio, and Paducah, Kentucky. One requirement of this GDP NCS Task, as defined by MMES, is a criticality evaluation of the Decontamination and Uranium Recovery Facility, X-705, at the Portsmouth Gaseous Diffusion Plant (PORTS).

An initial report 1 on the Decontamination and Recovery Facility presented a general overview of the facility and NCS documentation. It also provided a breakdown of X-705 into systems, subsystems, and operational areas, each of which could be evaluated in a separate report. For reference, the breakdown of X-705 presented in the initial report is repeated as Table 1.1 below.

This report is one of the series of follow-on documents that assesses nuclear criticality safety in $X-705$. As required by MMES Job Request $X-32$, this document evaluates in detail the specific operational area of Spray Booth Operations.

For the reader unfamiliar with $X-705$, the spray booth facility can be visualized as similar to a car wash. Large equipment, primarily from the enrichment cascade, is decontaminated by spraying it with one or more acid solutions and rinse water, as it moves on a dolly through a series of five booths (two citric acid, one nitric acid, one rinse water, and one drying. booth). Located near the center of the high bay area, these booths are a steel structure, often referred to as the tunnel. The basement of the tunnel contains storage columns for the recycled acid cleaning solutions. A detailed description of Spray Booth Operations is provided in Section 3.0 of this report, and a schematic is illustrated in Figure 3.1.

Section 2.0 summarizes the top-level conclusions of this evaluation. A general description of Spray Booth Operations and related hardware is presented in Section 3.0. Section 4.0 identifies and discusses the NCS documentation applicable to Spray Booth Operations, a concise listing of which is provided in Appendix A. Section 5.0 assesses in detail the NCS control parameters and develops a consolidated list of administrative controls and safety systems. An overall assessment of criticality safety is provided in Section 6.0, and recommendations for further consideration are suggested in Section 7.0. 


\section{SYSTEM/ SUBSYSTEM/ OPERATIONAL AREA}

1.0 Decontamination (High Bay)

1.1 Large Parts Disassembly \& Decontamination (C Area)

1.1.1 Compressor Disassembly

1.1.2 Convirter Disassembly

1.1.3 South Annex Operations

1.1.4 Spray Booth Operations

1.1.5 Truck Alley Cleaning

1.1.6 General Storage and Handling

1.2 Small Parts Cleaning (A Area)

1.2.1 30-in. and 48-in. Cylinder Cleaning

1.2.2 8-in. and 12-in. Cylinder Cleaning

1.2.3 5-in. Cylinder Cleaning

1.2.4 Cylinder Drying, Conditioning, and Testing

1.2.5 Sodium Fluoride Pellet Conditioning

1.2.6 Seal and Small Parts Dismantling

1.2.7 Small Parts Handtable Operations

1.2.8 Small Parts Pit Operations

1.2.9 Sand and Glass Blasting

1.2.10 General Storage and Handling

1.2.11 Trichloroethylene Degreasing

\subsection{Vacuum Cleaners}

2.0 Uranium Recovery (B Area)

2.1 Mixed Acids Precipitation (A Area)

2.2 Trap Material Leaching 2.2.1 Spray Tank Operations (A Area)

2.2.2 Flocculating Columns/Nacuum Filter Table 2.2.3 Unmeasured Storage

2.3 . Fluorides-Complexing Handtable (A Area)

2.4 Recovery/Blending Handtable Operations

2.5 Measured Solution Storage (B-36, B-38, B-1)

2.6 Volume Reduction/Chemical Processing

2.7 Calciners

2.8 Nitrogen Oxide Scrubbers

2.9 Raffinate Storage

2.10 Heavy Metals Precipitation

2.11 Technetium lon Exchange

2.12 General Storage and Handling

2.13 Continuous Dissolver

2.14 Mixed Acids Precipitation (B Area)

2.15 Neutralization System

2.16 Incinerator 


\section{Table 1.1 Breakdown of X-705 (continued)}

\section{SYSTEM/ SUBSYSTEM/ OPERATIONAL AREA}

3.0 Oxide Conversion (E/F/H Area)

3.1 UNH Calciner (F Area)

3.2 General Storage and Handling

4.0 Waste Water Treatment Systems

4.1 Condensate Recovery

4.2 Rinse Booth Recirculating Storages

4.3 Cylinder Solution Microfiltration

4.4 Oil and Grease Removal Unit

4.5 Solution Collection and Storage

4.6 Microfiltration/Pressure Filtration

4.7 Effluent Pumping Station

4.8 Tunnel Sumps

4.9 General Storage and Handling

5.0 Support Areas

5.1 Maintenance Shop (D Area)

5.2 Process Laboratory (G Area)

5.3 Laundry

5.4 Office Area

5.5 Acid/Solvent Receiving, Storage, Transfer (H Area)

5.6 Ventilation, Exhaust, and Utilities

5.7 Drains

5.8 General Storage and Handling

5.9 Miscellaneous

Notes:

(1) Systems, subsystems, or operational areas that are no longer operational are indicated with italics.

(2) A category of "General Storage and Handling" has been added to various systems and subsystems to include activities that are difficult to assign specifically to a given area. 


\subsection{SUMMARY CONCLUSIONS}

Additional administrative controls and/or physical modifications of the spray booths are required in order to comply with MMES standard practices and current DOE Orders. The risks of processing equipment contaminated with highly enriched uranium are significantly higher than those with equipment from the lower end of the cascade. Several issues should be resolved prior to the large-scale decontamination required by the HEU Suspension Program.

NCS concerns on Spray Booth Operations can be summarized in four general areas:

\section{Initial Inspection Procedures}

Current procedures, at least as documented, do not provide sufficient assurance that an unsafe deposit does not exist in the contaminated equipment or that cleaning solution cannot collect in an unsafe geometry. Clarification of inspection procedures is required, and the development of standard plans is recommended for positioning of equipment so that solution is not collected.

\section{Unfavorable Geometry under Rinse Booth Floor}

The storage volume for the rinse booth solution is limited, and any overflow enters an unfavorable geometry under the floor grate. The situation is exacerbated by the fact that the rinse booth is the final collection point for most other overflows and scavenger systems. Current procedures rely on level sensors to warn the tunnel operator that overflow into the unfavorable geometry is imminent. These sensors are not documented or tested as safety systems, but it is doubtful that they would comply with DOE Orders and NCS standards in any event.

The unfavorable geometry resulted essentially from a modification of the rinse booth storage that was necessitated by environmental issues. Although several options are available to address the NCS concerns of this modification, the corrective actions have both operational and cost/schedule impacts and should be carefully considered by operational, criticality, and engineering personnel.

\section{Qutdated Documentation}

Spray booth operations are complex and are supported by a rather large number of operating procedures. A number of significant changes to the tunnel and its basement have been implemented, and current documentation does not reflect these changes. The most noteworthy concern pertains to storage configurations and valve/piping arrangements for solution transfer. Priority should be given to updating operating procedures, but engineering drawing records are also in need of revision. 
Except for the rinse booth mentioned above, no potential situations were identified that could result in transfer of fissile solution into an unfavorable geometry within the spray booth itself. However, as discussed in Section 6.4, some solutions from the basement storage are transferred to an unfavorable geometry during Recovery Operations.

\section{Qther Potentially Unsafe Geometries}

Several other areas of geometry concern need to be evaluated for physical modification or documentation of their cost/risk analysis. Resources should be provided for general maintenance of the floor in the tunnel basement and elimination of its standing pools of solution. The scavenger pump in the tunnel basement appears to be of unfavorable geometry and should be replaced by a smaller unit. The requirements for separation of uranium-bearing solutions from water/air lines should be established (or clarified) plant-wide and implemented in X-705. 


\subsection{DESCRIPTION OF SPRAY BOOTH OPERATIONS}

This section presents a summary of the Spray Booth Operations, its related equipment, and the input/output streams of fissile material. A detailed step-by-step description of these procedures is contained in Operating Methods RD 2.2 and RD 2.4. Specific instructions for the dolly operation and for acid-solution preparation are presented in RD 2.3 and RD 2.10, respectively. Special requirements for handling technetium bearing equipment are discussed in RD 2.2.2.

\subsection{Procedures and Equipment}

Large equipment from the cascade is decontaminated in the X-705 spray booths, located near the center of the high bay. The five booths (discussed below) comprise a steel structure often referred to as the tunnel. Equipmient such as compressors, valves, and possibly converters is first disassembled in the South Annex and/or the area northeast of the spray booths, where the majority of nonvolatile uranium deposits are removed by scraping, brushing or vacuuming. Equipment awaiting spray booth decontamination is oriented or covered so that solution (e.g., from a possible leak in the overhead storage system) cannot collect in an unsafe geometry.

Equipment entering the tunnel is loaded onto one of five stainless-steel dollies and again oriented to prevent accumulation of cleaning solution in an unsafe geometry. Some large parts have special fixtures that facilitate proper positioning on the dolly and/or rotate to optimize spray coverage. Each dolly.has a stainless steel frame with four flanged wheels that ride on tracks, and both dolly ends have a drivepin assembly. One or both pins are dropped into the links of a conveyor chain that pulls the dolly. Protective and limit switches prevent inadvertent dolly movement (e.g., during spraying operations).

The spray booths are shown schematically in Figure 3.1. The facility consists of a tunnel with five serial booths, each separated by a retractable isolation curtain. Each of the first three booths recirculates the acid solution used for decontamination. Booths \#1 and \#2 use approximately 0.3-molar citric acid, and booth \#3 uses 3.0-molar nitric acid. The spray is directed at the sides and on the top of the parts. The decontamination solution drains through floor grates and onto inclined floor segments, which channel it to 28 drain pipes, 14 on each side of a booth. Each drain pipe leads to a geometrically-favorable 5 -in. vertical storage column in the tunnel basement. The solution in these storage columns is recycled through the spray heads by individual pumps (one per booth) in the tunnel basement until the dissolved solids or uranium concentration necessitates changeout. (Actually, the west side of the tunnel basement in each acid booth contains 13 , not 14, storage columns. The space for the missing storage column is occupied by a 3.5-in. pipe that carries acid solution to the spray heads. This minor difference is ignored in the discussion and analysis that follows.) 


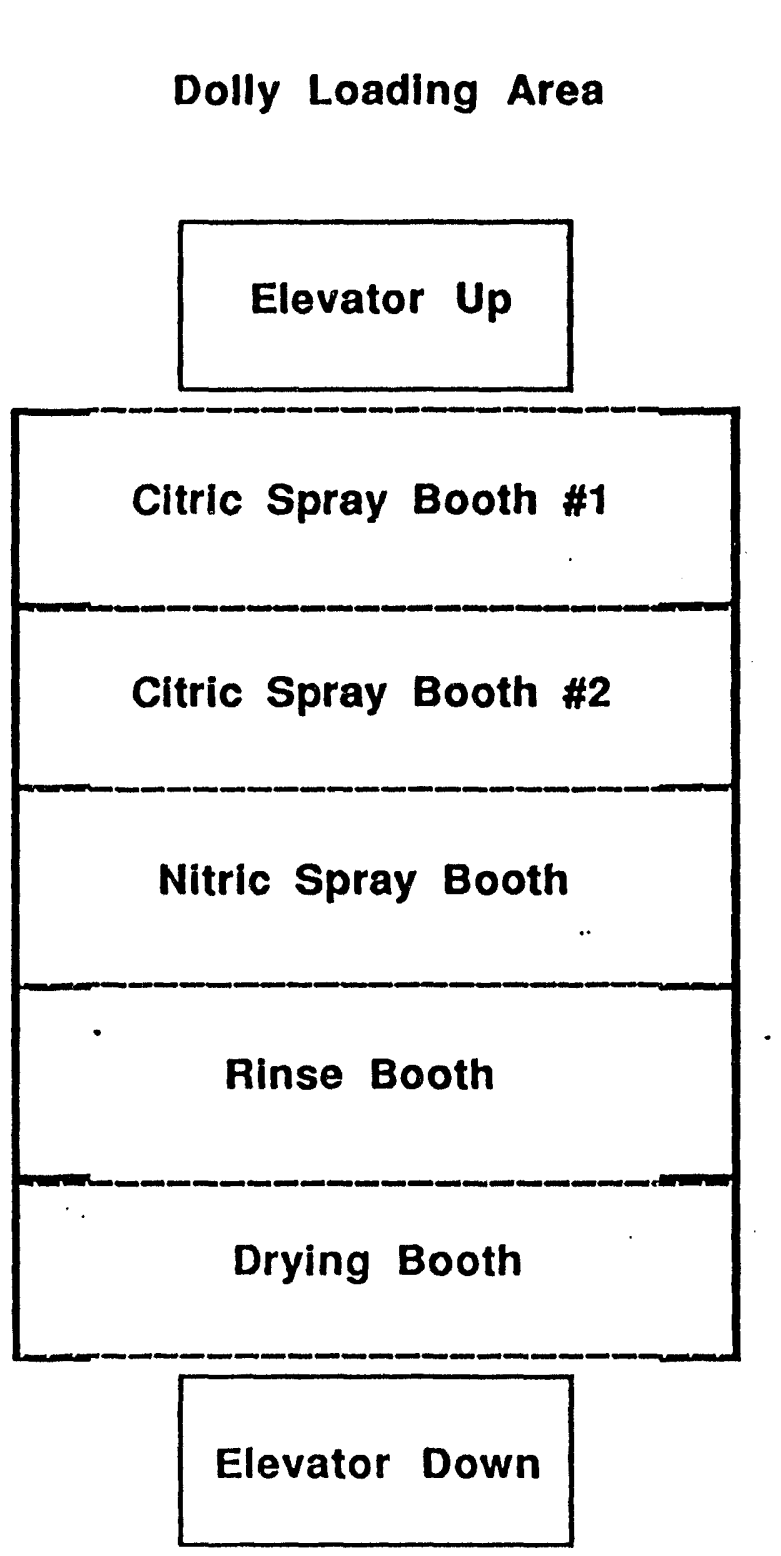

Figure 3.1 Schematic of $X-705$ spray booths 
Solution changeout is required when a visible coating remains on the parts after cleaning, when a radiation survey of the parts indicates high residual contamination, or (perhaps) when the uranium concentration in the solution exceeds a specified limit. During changeout the contaminated acid solution is pumped into the tunnel unmeasured storage columns at the southern end of the tunnel basement, where it awaits further processing in the uranium recovery area.

Copper, steel and Monel parts are normally cleaned only in the citric acid booths. However, if the uranium deposits are not removed by citric acid, these parts may be cleaned with nitric acid provided the residence time is limited to less than five minutes and the parts are immediately rinsed with water. Scrap aluminum parts are often left in the booths to complex fluorides and hinder hydrofluoric acid buildup in the recycled citric acid solution. The spray duration for parts in each citric booth is approximately 45 minutes. After the parts are allowed to drain, the operators enter the booth to hand clean, brush, or sponge any visible contamination remaining in flanges, bolt holes, or other surfaces. The dolly is then moved to the next booth. Aluminum parts can also be sprayed with nitric acid for 30 minutes or more, as necessary. Generally parts are decontaminated in either citric booth \#1 or \#2, but not both. Particularly contaminated parts may be cleaned sequentially through both booths.

The fourth booth is dedicated to rinsing the cleaned parts with water. Where possible, the parts are usually rinsed manually with a hand-held spray wand. Sometimes recirculating rinse water solutions are sprayed through overhead nozzles, by a pump in the tunnel basement, onto the parts to rinse off any residual contaminated acid solutions. The rinse solution drains through a grate and onto two separate inclined floor channels, which drain into a horizontal 8-in. pipe. This pipe connects to five 5 -in. horizontal rinse storage columns near the ceiling in the tunnel basement. When the horizontal tunnel rinse storage is full, it can be transferred to the geometrically-favorable microfiltration storage (overhead pond) near the ceiling in the high bay.

In the final booth the parts are generally allowed to air dry, although a combination of vent fans and warm air can be used if desired. After the parts are dry, the dolly is pulled onto the south elevator. If large-scale contamination remains, the parts are not removed, and the entire dolly is returned to the north end of the spray tunnel, as discussed in the next paragraph. If large-scale contamination is not present, the parts are unloaded by cranes onto pallets on the floor. The parts are then inspected for visible uranium contamination, surveyed for alpha and beta radiation, and then tagged appropriately. Parts which are found to have unacceptable contamination are further hand cleaned with air-driven wire brushes or sponges and acid, as required.

After the dolly is unloaded (or if the parts need to be sent through the tunnel again), it is lowered on the south elevator to the tunnel basement. There it moves on another set of tracks (with a second chain drive) to the north end of the basement, 
where it stays until needed for cleaning other large parts. It is then ioaded on the north elevator and raised to the high-bay floor level for reuse.

The tunnel basement contains seven storage banks; each with 28 geometrically favorable vertical columns (14 on each side). Each column is a 5 -in. diameter pipe, approximately 24-ft. in height, and separated by a 12 in. by 12 in. paraffin column for isolation purposes. Figure 3.2 shows the arrangement of these vertical storage banks, each of which has a volume of about 2000 liters. The citric and nitric storage and the tunnel unmeasured storage were discussed above. The tunnel measured storage (just north of the unmeasured storage) is used for contaminated acid whose volume, uranium concentration, and assay have been measured in the B-38 measuring columns in the uranium recovery area. (This storage provides additional, but comparable, capability to the B-1 columns in recovery.) When recovery personnel are ready to process the solution in measured storage, it is transferred to (generally) the Cloop pre-evaporator by a pump in the tunnel basement. The two banks of columns at the north end of the tunnel basement are used to store aqueous raffinate, which results from the extractor-stripper process in Uranium Recovery. These two banks are essentially equivalent. When recovery personnel are ready to process the raffinate, it is transferred to heavy metals precipitation by a pump in the tunnel basement.

The storage configuration in the tunnel basement is very flexible. The large number of pumps and valves basically enables the transfer of solution from each storage bank to any other storage bank, although transfer to measured storage requires the unlocking of a valve. In fact, as will be mentioned in Section 4.0, over the years the use of the various storage banks has changed significantly, apparently without a major reconfiguration of the piping system. NCS concerns of such flexibility are discussed in Section 6.0.

Also shown in Figure 3.2 is the rinse booth storage that was mentioned earlier. The five 5-in. horizontal pipes have a capacity of about 750 liters. Unlike the vertical storage, the ability to transfer solution from the rinse booth storage is rather limited. The design-procedure is to pump this storage to the overhead pond. A make-shift capability does exist to transfer the rinse booth storage solution to the nitric acid booth if necessary (e.g., if the uranium concentration in the rinse booth is above the limit allowed for the overhead pond).

\subsection{Input and Output Streams of Fissile Material}

One input stream of fissile material to the spray booths is the nonvolatile uranium deposits that are present on the large parts entering the tunnel. These deposits are dissolved by the citric or nitric acid cleaning solutions and are initially collected in the citric or nitric acid storage columns, respectively. (In this report, the resulting nitric acid solution is treated as $\mathrm{UO}_{2}\left(\mathrm{NO}_{3}\right)_{2}$; the citric acid solution is treated as $\mathrm{UO}_{2} \mathrm{~F}_{2}$ for modeling purposes.) During the changeout of these solutions, both the contaminated citric and nitric acid are transferred to the tunnel unmeasured storage. A 

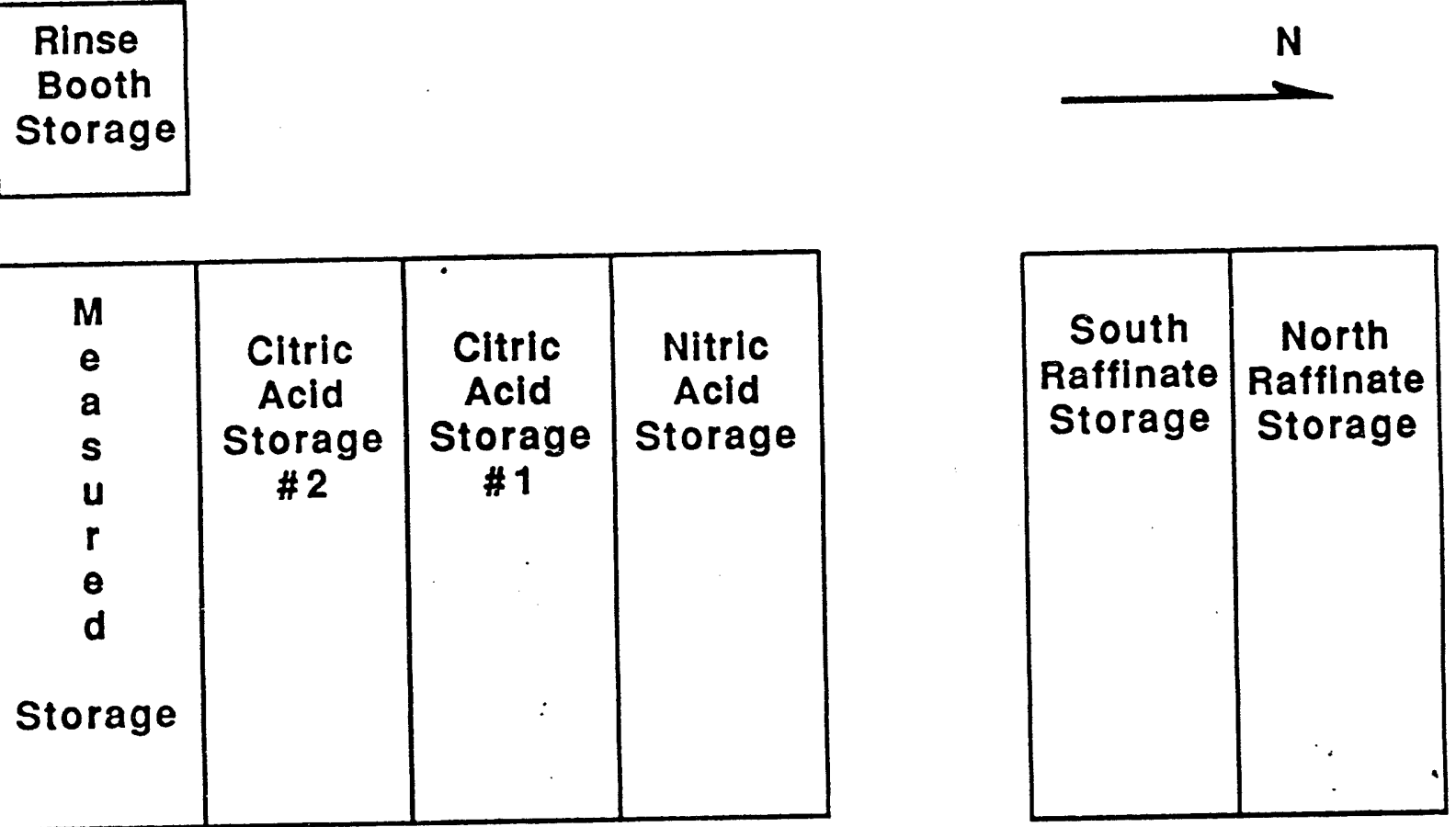

Figure 3.2 Schematic of solution storage configuration in tunnel basement 
second input stream of fissile material to the spray booths is the nitric acid solution from the Group I handtables in the small parts $(A)$ area, which is also transferred to the tunnel unmeasured storage. The output stream from the tunnel unmeasured storage is eventually transferred to the B-38 columns in the recovery area for measurement of volume, uranium concentration, and assay. These input/output streams are shown schematically in Figure 3.3.

When equipment enters the rinse booth, it still contains traces of uraniumbearing acid solutions, which mix with the rinse water. (This is indicated in Figure 3.3 by the arrow from Acid Storage Solution to Rinse Booth Solution.) The resulting lowconcentration solution $(<500 \mathrm{ppm})$ is transferred to the geometrically-favorable storage system (overhead pond).

As can also be seen in Figure 3.3, several fissile streams are input to the storage banks in the tunnel basement, although they do not (usually) enter the spray booths themselves. Uranyl nitrate measured in the B-38 columns in the recovery area can be transferred to the tunnel measured storage as an alternative to the B-1 columns before being processed through the C-loop pre-evaporator. Likewise, raffinate from the extractor-stripper process (with very low uranium concentration) is transferred to the raffinate storage columns in the north end of the tunnel before being processed through heavy metal precipitation.

A discussion of the flow of contaminated solutions in the tunnel would not be complete without considerations of the overflow and scavenger systems. Overflows from the citric and nitric acid storage, as well as leaks from their pumps, are collected in a geometrically-favorable pipe. On signal from a level sensor, this solution is automatically pumped into tunnel unmeasured storage. Overflow from the tunnel raffinate storage vents to the \#2 citric acid booth, and overflow from tunnel measured storage vents to the nitric acid booth. Leaks which result in accumulation of solution on the basement floor are scavenged by a manually-operated steam-jet system and transferred to tunnel unmeasured storage. Finally, and perhaps most significant from an NCS standpoint, overflow from the tunnel unmeasured storage and solution from back-flushing the filters vent to the rinse booth. Two level sensors are installed on the 5-in. rinse storage bank, just before the junction with the 8-in. pipe (an unfavorable geometry). The requirement to classify these sensors as safety systems is discussed in Section 5.0.

A ground water sump is located at both the north and south ends of the tunnel basement. These sumps [SS4.8] should contain essentially no uranium and will be examined in a later report. 


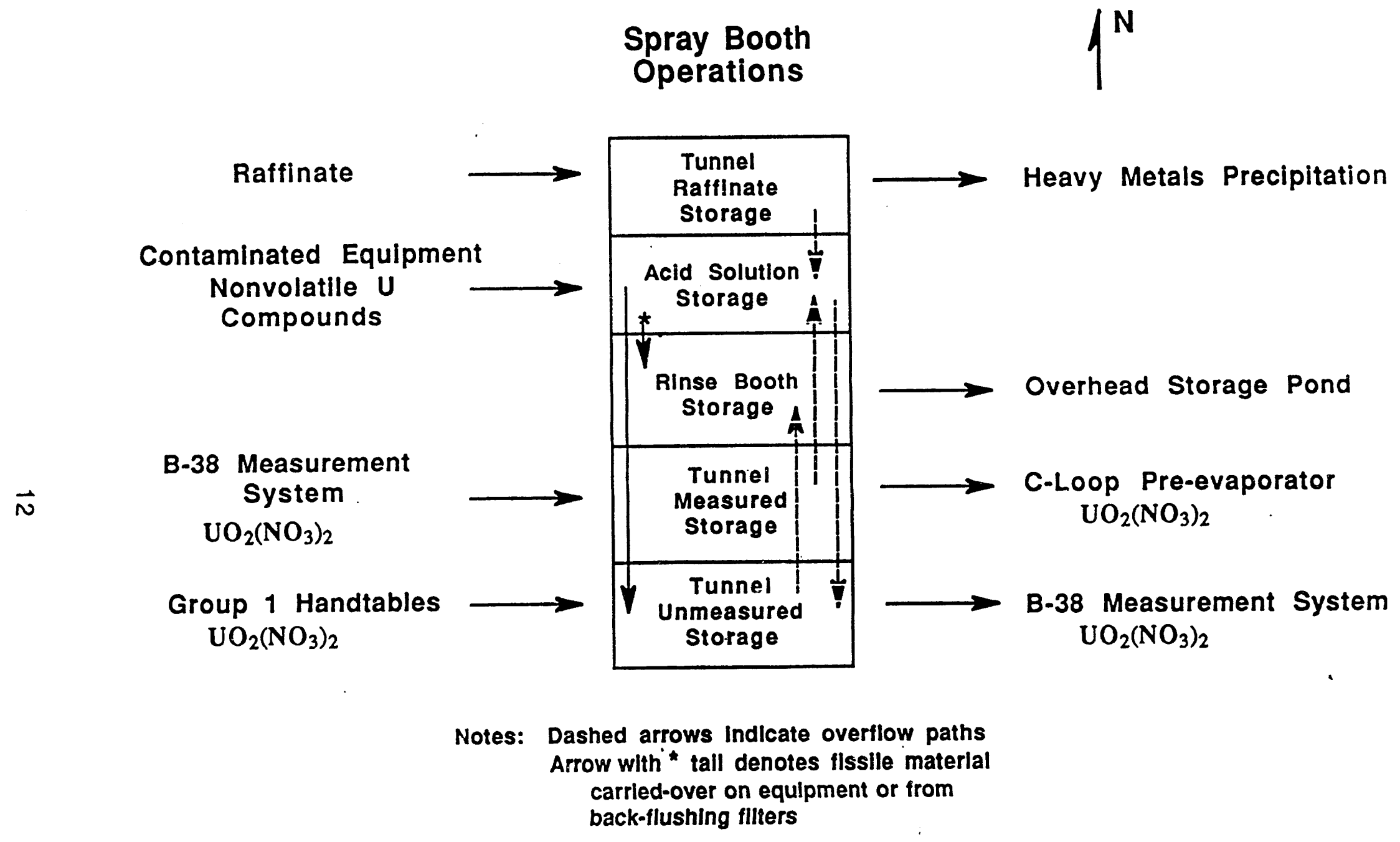

Figure 3.3 Schematic of input and output streams of fissile material 


\subsection{EXISTING NCS DOCUMENTATION}

The operation of the spray booth is a rather complex procedure. It is supported by a substantial number of documents, all of which contain some information relative to nuclear criticality safety.

Existing documentation on Spray Booth Operations is discussed in the following sections. A concise listing of this documentation is summarized for convenience in Appendix $A$.

\subsection{Final Safety Analysis Report (FSAR)}

An overview of Spray Booth Operations is provided in the FSAR3, Section 4.3.1.3.1.4, which was last revised in 1990. Although relatively up-to-date, a few changes were not incorporated into the revision. The most significant of these changes is the division of the $\mathbf{5 6}$ columns for contaminated acid storage at the southern end of the tunnel into two separate storages. The southern 28 columns (14 on each side of the tunnel) are now referred to as tunnel unmeasured storage, but perform the same function as the previous contaminated acid storage. The 28 columns ( 14 per side) immediately north of the tunnel unmeasured storage are now utilized for tunnel measured storage and provide an additional capacity for Uranium Recovery [S2.0] similar in purpose to the B-1 columns in Area B. In general, this change has not been incorporated into any of the documentation on Spray Booth Operations, including facility change agreements (FCAs) and operating methods or procedures.

Accident scenarios for Spray Booth Operations are discussed in Section 5.3.1.4 of the FSAR. The only potential criticality accident considered is the rupture of all storage columns in the tunnel basement, and the risk is rather quickly dismissed as being of extremely low probability. Additional off-normal and accident events are presented in Section 6.0 of this report.

Sections 4.3.2.2.1 to 4.3.2.2.4 and Section 5.3.2.2.1 of the FSAR are somewhat confusing. Although the numbering system of these sections would indicate that they apply to the Waste Water Treatment System [S4.0], a more careful examination reveals that these sections are almost a repeat of the Operational Safety Requirements (OSRs), discussed in Section 4.4 of this report, and cover many of the operational areas in X-705. A significant difference between these sections of the FSAR and the OSRs is noted in Section 5.1.1.6 of this report.

\subsection{Development Memos (DMs)}

The only current DM that contains information on Spray Booth Operations is DM 8684, Rev. 4, pp. 99-100. Revised in 1984, this document is rather outdated. Moreover, a review of superseded DMs on Spray Booth Operations (DM 732 and 
DM 445) indicated that the basic information in DM-868 has not changed substantially since 1956.

Because DMs are defined by MMES to be guídance documents5, their provisions need not necessarily be incorporated into procedures. Two such provisions of DM-868 deserve further discussion:

\begin{abstract}
Any piece of equipment not readily cleaned of all but a film of material, or any piece showing evidence of damage or internal accumulations should not be put in the tunnel, but should be given special treatment, after consultation with Nuclear Criticality Safety.

The system appears to be safe if ... the U-235 concentrations of all solutions handled in the system are kept below 27,500 ppm U-235 (27.5 g U-235/ liter; i.e., 27,500 ppm uranium for Group II, 137,000 ppm uranium for Group I).
\end{abstract}

The first of these restrictions does not appear in any other documentation on Spray Booth Operations. As will be discussed in Section 5.0, several administrative controls deal with limiting the volume of cleaning solutions, but no instructions warn the operator to consider the amount (mass) of uranium-bearing material.

The second provision is somewhat troublesome. The basis for this limiting concentration is stated as the C-12-4 pump (and near-by piping) in each of the three acid spray booths. A considerable effort appears to have been devoted to maintain safe geometry wherever possible in the tunnel, and the existence of pumps that require concentration controls seems to negate that effort. DM-868 does indicate that the concentration limit is conservative. As will be discussed in Section 5.0, the pumps discussed in DM-868 appear to have been replaced in the 1970s. An analysis of the current pumps is presented in Appendix B and Appendix $C$, and summarized in Section 5.0. Nevertheless, it is worthwhile to note at this time that the concentration limit is essentially ignored in current spray bootin operations. Although it is posted as a warning sign at the front of the tunnel, it is not contained in any of the operating procedures or Operational Safety Requirements.

\title{
4.3 Facility Change Agreements (FCAs)
}

The only FCA that deals directly with Spray Booth Operations appears to be FCA-3566, which summarizes changes to the rinse booth that were implemented when the geometrically favorable storage system (overhead pond) was added to $X-705$. This FCA also establishes a concentration limit of $5 \mathrm{gU} / \mathrm{l}$ for the rinse booth storage. The two level sensors on the 5-in. rinse booth storage are net mentioned.

In addition, FCA -3057 prescribes numerous signs for NCS administrative controls and limits that should be posted throughout X-705. Two such signs are mentioned for the tunnel. The first states that equipment should be disassembled and oriented so that cleaning solution will not be retained in an unsafe geometry. The 
second sign indicates that the $235 \mathrm{U}$ concentration should be limited to $27.5 \mathrm{~g} / \mathrm{l}$. The purpose of this FCA is merely to establish sign requirements for controls that were apparently prescribed by other NCS documents. Since no current documents appear to mandate a concentration limit, it is questionable that concentration limits are still intended.

The fact that only one FCA discusses Spray Booth Operations is rather surprising. Although this report does not attempt to document the historical development of the tunnel, the following changes have apparently been implemented over the years without any FCA for approval:

(1) A section of the tunnel that once contained two rinse booths now contains a nitric acid spray booth and one rinse booth.

(2) The northern most storage columns in the tunnel basement were converted from contaminated acid storage to raffinate storage.

(3) Citric acid was substituted for carbonate as the primary cleaning solution.

(4) As noted earlier, the southern most storage columns in the tunnel basement have been separated into measured and unmeasured storage.

(5) Overflow lines have been routed to different locations.

(6) The original nitric acid booth is now a citric acid spray booth.

(7) Several pumps were replaced with different models and sizes.

Although such changes might have been authorized based on a documented Engineering Services Request (ESR), a cursory review of the files did not locate any such information.

Each of the above changes required both physical and procedural modifications. Concerns that they have not been properly documented or reviewed are presented in Section 6.0 of this report.

\subsection{Operational Safety Requirements (OSRs)}

The OSR8 for X-705 designates three restrictions for Spray Booth Operations. Section 2.8 limits the maximum uranium concentration of the rinse booth solution to $5 \mathrm{~g} / \mathrm{l}$. Section 3.3.3 requires that the status of the storage columns and tunnel floor be monitored every four hours when in operation, and Section 5.3.2.3 specifies that equipment will be positioned in the rinse booth such that solution will not be collected or retained in an unsafe geometry. An analysis of the adequacy and completeness of these OSRs is presented in Section $\mathbf{5 . 0}$ of this report. It is noted here, however, that 
the restriction on accumulation of solution in an unsafe geometry is relevant to all booths, not just the rinse booth as stated in the OSR.

\subsection{Operating Methods (OMs) and Procedures}

OMs are detailed procedures written to provide step-by-step instructions for PORTS personnel on how to execute a given operation. Recently the nomenclature for these documents has been changed to In-Hand Procedures (IPS), Reference Procedures (RPs), and other types of Procedures, depending on their intended use. As Operating Methods are revised, the designation of OM will gradually disappear. Although all such documents for Spray Booth Operations are still designated as OMs, the terms should be considered synonymous for this report and others in the series.

As discussed in Section 3.0, the spray booth is a rather complex operation. The operator needs to understand procedures for operating the dolly system, mixing acid solutions, operating the spraying devices, and transferring solutions to storage locations. In addition, he must be knowledgeable in decontamination requirements to prevent acid damage to certain metals and be familiar with extra precautions that should be taken in special situations, such as high technetium contamination. As a result, five OMs deal specifically with Spray Booth Operations, and at least four additional OMs provide supporting information.

\subsubsection{RD 2.2. Decontamination of Large Parts9}

This $O M$ is the general procedure for decontamination and handling of equipment to be cleaned in the tunnel. More specifically, it deals with proper solutions, contact times, and hand-cleaning and buffing procedures.

Four criticality safety considerations are explicitly designated. Because these considerations occur in other documentation, it is probably worthwhile to discuss them at this point.

The first three safety considerations essentially deal with ensuring a safe geometry for the equipment on the dollies. The operator is instructed to load equipment so that cleaning solutions cannot accumulate in an unsafe geometry, to ascertain visually that uranium deposits are not contained in an unsafe geometry, and to assure that no blockage prevents solutions from draining off the dollies. The fourth safety consideration states that the maximum uranium concentration in the rinse booth [solution] is $5 \mathrm{~g} / \mathrm{l}$. The first and last safety considerations are denoted with an OSR stamp, indicating that these restrictions are imposed by the OSR.

Several criticality considerations are notably not included in this OM. First, the operator is not instructed to limit the mass of uranium. (DM-868 recommends that only a film of uranium contamination be allowed.) This omission implies that mass is not one of the control parameters, which are discussed in Section 5.0. Second, no 
uranium concentration limits are established for the acid solutions, and, in fact, no concentration checks are really required by the procedures. The criterion for changing out the acid solutions is essentially that the solution becomes so dirty that it leaves deposits on the equipment or that the equipment cannot be decontaminated using the acid spray. (DM-868 suggests that $235 \mathrm{U}$ concentration be limited to $27.5 \mathrm{~g} / \mathrm{l}$, or 27,500 ppm.) Finally, although three considerations warn the operator about unsafe geometry, no guidance is presented on what constitutes an unsafe geometry, and no loading instructions are provided to assist the operator on how to position particular items of equipment so that a safe geometry is assured.

\subsubsection{RD 2.3. Operation of the X-705 Spray Tunnel Dolly Motive System 10}

This OM provides detailed procedures and guidelines on operating the dollies and motive units to transport large parts through the tunnel. Most of this document is not very relevant to NCS, although two criticality safety considerations are presented. The operator is instructed to check the dolly drain holes to assure they are not plugged and to orient parts so that solutions cannot accumulate in an unsafe geometry. The later consideration is intended to be designated with an OSR stamp, although the addendum prescribing the OSR stamp erroneously indicates Section 3.3.2 instead of Section 3.2.2.

\subsubsection{RD 2.4. Operation of the Spray Booths11}

This procedure provides very detailed instructions for operating the spraying equipment, mixing the acid solutions, and transferring solutions from one set of storage columns to another. It provides a very good (but outdated) schematic of the storage columns and piping systern in the spray booths. From an NCS standpoint it contains the most detailed and relevant information.

The four NCS considerations are essentially identical to those presented in RD 2.2. However, an OSR stamp is conspicuously absent from the requirement to assure that solutions cannot accumulate in an unsafe geometry. The criticality considerations noted as being absent from RD 2.2 are also not present in RD 2.4.

Although RD 2.4 has been revised as recently as May 1992, it still does not incorporate the changes implemented by separating the contaminated acid storage (the southern most 56 columns) into a measured and unmeasured storage. (This modification was clearly implemented prior to 1992.) It also does not include the change of the northern-most 28 columns from north acid storage to raffinate storage. Consequently, the detailed instructions and valve positions for transferring solution from one location to another no longer reflect the actual storage configurations and piping arrangements. The criticality concerns of such omissions are discussed in Section 6.0. 


\subsubsection{RD 2.10. Spray Tunnel Solution Makeup and Adjustment12}

This OM provides procedures on preparing the citric and nitric acid solutions, maintaining their proper $\mathrm{pH}$, and adjusting these solutions for transfer to contaminated acid storage (tunnel unmeasured storage). Although this $O M$ has not been revised since 1988, its scope is limited to the solutions themselves, not details of the storage locations, so that the changes discussed in the previous paragraph are not relevant to RD 2.10.

The only safety consideration listed for criticality is a generic comment that contaminated solutions should be handled in an always safe manner.

Unlike the other OMs, however, this OM does specify that acid solutions should be sampled for uranium concentration and assay prior to transfer to contaminated acid storage (now unmeasured storage). On the other hand, it does not provide limits or any guidance on decisions that might be made based on the results of that sampling. (For that matter, it does not even specify that the sample results are to be recorded.)

\subsubsection{RD 2.2.2. Guidelines for Decontamination of Technetium Bearing Equipment13}

The scope of this $\mathrm{OM}$ is limited to special handling and procedures required for equipment contaminated, or suspected to be contaminated, with technetium. Although not specifically stated, this would seem to imply that it would be most applicable for equipment contaminated with highly enriched uranium, since technetium is of most concern at the upper end of the cascade.

This OM prescribes two criticality safety considerations. Equipment must be disassembled to assure that uranium deposits are not contained in an unsafe geometry, and parts must be oriented so that cleaning solutions cannot collect in an unsafe geometry. Like the OMs discussed above, geometry is thus identified as a control parameter, but mass is not. Since OM RD 2.2.2 has not been revised since 1985, it was published before the OSR designations were noted.

Although rather short (only three pages), this OM does contain a provision for sampling the acid solutions for uranium content. The operator is instructed "when necessary" to sample the booth solutions and send the samples to the $X-705$ or $X-710 \mathrm{Lab}$ for technetium and uranium concentration analysis. If the uranium concentration is greater than $1500 \mathrm{ppm}$ (or the technetium concentration above a specified amount), the solutions are to be transferred to contaminated acid storage, and acid booth lines are to be flushed before new solutions are prepared. Transfers and sample results are to be recorded.

Although the "when necessary" is not specifically defined, the tone of the discussion appears to be focused on concern for technetium concentration, not criticality. As a result, it does not appear if these instructions have any direct bearing on NCS considerations. 


\subsubsection{Qther Related QMs}

Four additional OMs are worth highlighting because they provide background on the decontamination process prior to equipment arriving at the spray booths. Although the purpose of this report is not to analyze these procedures, they are, in fact, an issue pertinent to the Double Contingency Principle.

RD 2.2.1, Special Handling of Equipment Containing Deposits of Uranium14, applies to the proper disposition of cascade equipment that may contain nuclear unsafe accumulations of uranium compounds. It defines two categories of handling procedures, Planned Expeditious Handling (PEH) and Uncomplicated Handling. PEH pertains to equipment that contains more than a safe mass of uranium, contains a deposit with water or oil, or contains deposits that cannot be sealed, buffered, or otherwise protected from additional moderation. Uncomplicated Handling deals with equipment that contains a dry deposit that is less than safe mass or is geometrically safe. (Note that equipment with a large mass, but geometrically safe and dry, appears to be categorized as Uncomplicated Handling.)

RD 2.2.3, Disassembly and Decontamination of Excessive Uranium or Technetium Bearing Equipment15, provides procedures for equipment disassembly and decontamination in the South Annex. Although this $O M$ is rather vague on which equipment is first decontaminated in the Annex, discussions with X-705 personnel indicated that large parts from the upper end of the cascade $(X-326)$ always begin in the Annex. (PEH equipment from other cascade buildings is also decontaminated in the Annex.)

CA-MP 8.3, Handling Equipment Containing Deposits of Uranium16, applies to the removal, storage, movement, and disposition of internally contaminated cascade equipment. It contains the same definitions for PEH and Uncomplicated Handling as does RD 2.2.1.

CN 8.3, Classifying Equipment Which Contains Deposits of Uranium17, describes procedures to estimate the uranium content and to classify equipment prior to its removal from the cascade. Based on neutron survey measurements, the total mass of uranium deposits is estimated. This estimated mass and the known assay are then used to determine whether PEH or Uncomplicated Handling is applicable. Contrary to the definition of Uncomplicated Handling, these procedures appear to indicate that a deposit in excess of safe mass will always result in a determination of PEH.

The above OMs were examined to determine what procedures are taken to assure that equipment to be decontaminated in the spray booth does not contain an unsafe mass of uranium. Although these documents indicate that a considerable effort is taken to remove deposits, they stop short of requiring that a visible inspection reveal 
no more than a film of uranium (as suggested by DM-868). The most definitive statement appears in RD 2.2.1, Section 8.3.2, which states:

When dismantling of "PEH" equipment is started, the job must be continued until disassembly is complete enough to ensure that no uranium deposits greater than a safe mass remain.

No criteria are discussed on how this determination of mass should be made, who is responsible for making it, or if such a decision is documented. On the other hand, especially for HEU, visual inspection is not a very reliable method for mass control. The control parameters for this aspect of Spray Booth Operations will be further addressed in Section 5.0 of this report.

\subsection{Engineering Drawings}

The number of engineering drawings relevant to Spray Booth Operations is enormous, and many of the drawings are designated as safety related. Appendix $A$ contains a partial list of some of the mechanical drawings for the spray booth fluid systems. Although these drawings were helpful, in general they are too outdated to be the definitive source of information. A few years ago an effort was apparently undertaken to verify drawings for $X-705$. Based on the fact that many of the drawings were "verified" on the same day and that several changes to the original design were not incorporated into the as-built drawings, the verification process appears to have been superficial. 


\subsection{CONTROL PARAMETERS, ADMINISTRATIVE CONTROLS, AND SAFETY SYSTEMS}

This section discusses each of the control parameters applicable to the various stages of Spray Booth Operations. A consolidated list of administrative controls is developed and compared with the controls listed in the OSR. Finally, a review of safety systems is presented.

\subsection{Control Parameters}

\section{1 .1 Geometry}

The spray booths appear to have been designed with geometry (combined with solid angle theory) as the primary control. Since the booths are intended for uranium of any enrichment, pipes are usually limited to 5 -in. diameter or less, and the separation of the pipes is generally large enough to prevent significant interaction (see Section 5.1.7 below). Nevertheless, in any operation as large as Spray Booth Operations, it is not surprising to find unfavorable geometries. Based on a review of drawings, operating procedures, and several walkdowns of the spray booth area, the following such geometries were observed.

\subsubsection{Rinse Booth Floor and Drain Pipe}

A cross section of the region under the floor grate in the rinse booth is illustrated in Figure 5.1. The rinse solution flows down the inclined planes, through a screen, into an 8-in. diameter pipe, and eventually down into a 5-in. diameter horizontal storage bank (not shown). Both the 8-in. pipe and the volume above it are unfavorable geometries. Consequently, a uranium concentration limit of $5 \mathrm{~g} / \mathrm{l}$ has been imposed on the rinse booth solution (see Section 5.1.6), and two sensors have been placed on the vertical section of the 5-in. diameter pipe just before it joins the 8-in. pipe. In the event the solution reaches the levels of these sensors, warning alarms sound to alert the operator.

The uranium concentration of the rinse solution is normally extremely low. Although the OSR limit is $5 \mathrm{~g} / \mathrm{l}$, the rinse solution is intended to be transferred to the overhead storage pond. A general restriction in X-705, which is net noted in the spray booth operating procedures, is that the maximum concentration of such solution is $0.5 \mathrm{~g} / \mathrm{l}(500 \mathrm{ppm})$. Therefore, one would not expect that the rinse booth solution would normally even approach its maximum allowed value.

On the other hand, Section 3.2 explained that overflow from the tunnel unmeasured storage empties into the rinse booth. The uranium concentration of the unmeasured storage solution may well exceed that permitted for the rinse booth. Situations of potential concern are addressed in Section 6.3.3. 


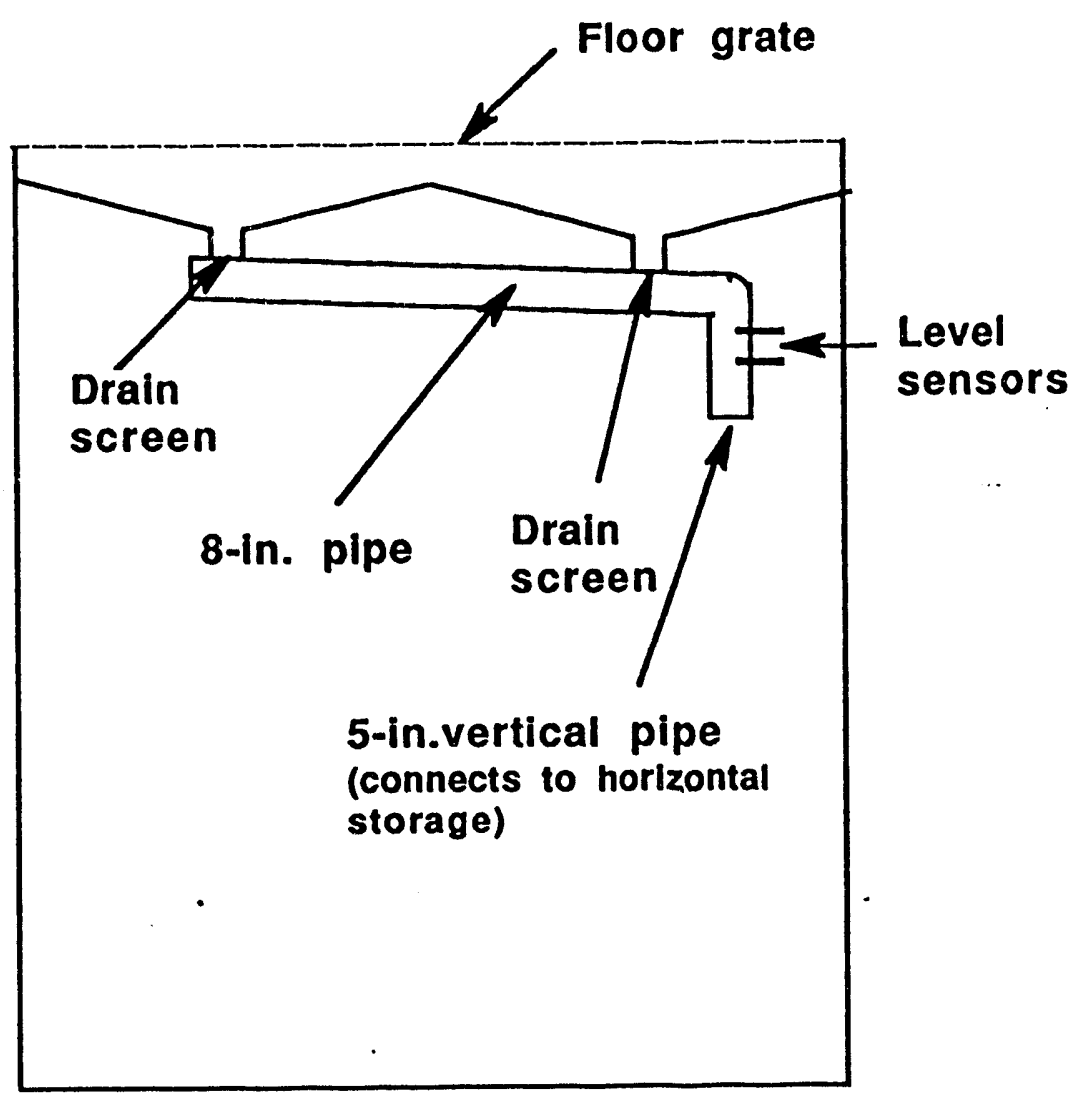

Figure 5.1 Geometry under rinse booth floor grate 
A major reconfiguration of this system would now be required to avoid these unfavorable geometries. Although the overall original design appears to have been based on safe geometry, a number of changes occurred over the years. The area now occupied by the rinse booth was at one time the second in a series of two rinse booths. As a result, the typical uranium concentrations were probably even lower than those at present. In addition, the contaminated acid storage (now tunnel unmeasured storage) originally overflowed into one of the acid spray booths, not into the rinse booth as it does now. Finally, before environmental issues were of high concern, the solution from the rinse booth simply drained to an outside holding pond, the 5-in. horizontal storage did not exist, recycling of rinse solution did not occur, and backup into the 8-in. pipe did not appear to be a potential problem.

\subsubsection{Acid spray booth floor and drain pipes}

Unlike the rinse booth, the citric and nitric acid spray booths drain to the far east and west sides of the tunnel. Instead of two drains, 28 drain pipes (14 on each side) connect with the 5-in. diameter storage columns in the tunnel basement. If all these columns are full, six overflow lines ( 3 per side) enable the acid solution to drain from the booth into a scavenger system, where it is pumped to the tunnel unmeasured storage. In the event that the pump fails to operate and the scavenger system fills, the solution spills onto the tunnel floor through the air-break that exists near the bottom of each overflow line. As a result, the overall system appears to be geometrically favorable and not of concern.

\subsubsection{Flour of tunnel basement}

As noted in the FSAR, the floor in the tunnel basement is approximately 160 feet by 20 feet. If the tunnel storage were filled to its maximum capacity (stated as 13,330 liters) and all pipes ruptured, about two inches of solution would accumulate on the floor. Although this is more than the always-safe geometry, the likelihood of its occurrence is very remote.

In addition, the total amount of uranium required for a 2 -in. critical slab is so large that this scenario does not appear credible. For example, ANSI/ANS 8.118 indicates that the single-parameter concentration limit for subcriticality is $11.6 \mathrm{~g} / \mathrm{l}$ of $235 \mathrm{U}$ for both uranyl nitrate and uranyl fluoride. If the entire solution of 13,300 I exceeded this concentration, over $150 \mathrm{~kg}$ of $235 \mathrm{U}$ would be in the tunnel storage! (DOE 5633.319 defines $\geq 20 \mathrm{~kg}$ of Group II $235 \mathrm{U}$ in a material balance area as a Category I quantity, with significant safeguards and security consequences.)

Other issues for the tunnel floor, however, are not as clear. In order to facilitate a scavenger system that collects leaks, a number of drain channels have been cut into the concrete. Over the years the acid solutions have taken their toll, and many of these channels appear to have increased in size. Although no quantification of this 
deterioration was attempted, it was noticed that pools had collected in some locations, and the solution more than filled the original drain channel.

The source of solution in these pools is not known at this time. One hypothesis is that small leaks exist in the extensive piping network in the tunnel basement. Another hypothesis is that ground water is seeping through the floor. Records indicated that the uranium concentration of these pools was as high as $\sim 6000 \mathrm{ppm}$ $(6 \mathrm{~g} / 1)$. In addition, some of the pools appeared to contain grease or oil.

Finally, if ground water is actually seeping in the tunnel basement, there could be a concern that uranium-bearing solution has been seeping into the ground.

\subsubsection{Steam condensate tank}

Although steam is no longer used in Spray Booth Operations, a number of old steam lines still exist in the tunriel basement. A steam condensate tank $\left(\sim 2^{\prime} \times 4^{\prime} \times 2^{\prime}\right)$, located along the west wall on the basement floor (near the crosswalk to the recovery area), is still functional for the steam system in recovery. Although contaminated solution would not normally be expected in the steam line, it appears as if the tank could be made geometrically safe (e.g., a long 5 -in. diameter pipe).

\subsubsection{Electrical boxes}

A number of electrical boxes exist in the tunnel basement. The concern over the unsafe geometry of such boxes is not unique to Spray Booth Operations and has been debated many times over the years in X-705. The OSR states that 1-in. holes will be drilled in all boxes with a void volume greater than $239 \mathrm{cu}$. in., but that requirement appears to be limited to the area of the Waste Water Treatment System. Because of the acidity of the air, the simple procedure of drilling holes in the bottom of such boxes has considerable drawbacks. One method employed in the recovery area was to provide a J-shaped drain (with PVC pipe) at the bottom of the boxes. These pipes are partially filled with antifreeze to keep out the air, similar to the trap on a typical sink.

\subsubsection{Connections to compressed air and water systems}

Several situations were observed in which the pipes for the spray solution were directly connected to the compressed air or water systems in X-705. Based on existing documentation, PORTS policy on such a practice is not clear. Although Section 4.3.2.2.2 of the FSAR indicates that air gaps are used on all water-to-process piping connections, Section 4.5 of the OSR provides a caveat that this design feature applies only to Uranium Recovery [S2.0]. Common NCS practice is to provide such a gap in order to prevent back-flow to an unsafe geometry.

The hand wands in the citric acid booth contain a valve arrangement that enables the operator to spray contaminated equipment with either acid solution, air, or a mixture of both. In addition to the manual valves (which might be open during 
operation), two check valves appear to be in place to prevent the acid solution from flowing into the compressed air line if pressure is lost. Assuring that these check valves are functional does not appear to be an easy task.

The acid solution flows from tunnel storage through a screen filter just prior to entering the spray booths. When the filter becomes clogged, the solution can be diverted through a second filter, and the clogged filter can be cleaned at the operator's convenience by backflowing water through the system. The water line for this backflow appears to be separated from the acid solution line by one manuallyoperated valve and (perhaps) a check valve.

As noted in RD 2.4 (Figure 1), a water line appears to connect directly (through one valve) with the overflow scavenger system. The walkdowns of the spray booths neglected to confirm whether this water line is still in place.

\subsubsection{Acid Measuring Tanks}

The three acid spray booths each contain an acid measuring tank on the west outside wall of the tunnel, although only the tank for the nitric acid booth is currently used. (Citric acid is merely poured through the floor grates.) These tanks are approximately 10 inches in diameter and 33 inches long. Both the vent and the drain of these tanks are separated from the spray booth by an air break. The valved input lines are for uncontaminated nitric acid and water only. Consequently, these geometries seem of no concern.

\subsubsection{Pumps}

As noted earlier, the existence of a concentration limit based on pump capacity implies that the spray booth pumps are not geometrically favorable. This subject will be addressed in Section 5.1.6 on concentration controls.

\subsubsection{Other}

A number of other large geometries exist in the tunnel but do not appear to be an NCS issue. For example, the hot air ventilation system in the drying booth does not appear to have any means to collect solution. It is noted, however, that the roof of the tunnel contains a very large area available for general storage. Because this area is directly under the overhead storage system in X-705, it is important that no objects that could collect solutions be stored on the roof. It is doubtful that this area is inspected regularly, so if the dilute solution of the overhead storage did collect here, long-term evaporation could increase the uranium concentration significantly.

\section{1 .2 Enrichment}

The tunnel is intended for large equipment from any part of the cascade. Consequently, no enrichment controls are applicable. 


\section{1 .3 Mass}

As noted earlier, the operating procedures for the spray booths place no restrictions on mass itself. Although it could be argued that the mass on any one item of equipment is controlled during South Annex and other disassembly procedures, the documentation prescribing such controls is not very rigorous, and tunnel personnel cannot verify the results. Clearly no mass controls on the spray booth solutions have been established. Consequently, this report assumes that uranium mass is not controlled.

\section{1 .4 Volume}

The operating procedures contain several warnings for the operator to assure that equipment is loaded on the dollies in a manner that prevents accumulation of solution in an unsafe geometry. No other guidance is presented, and no loading plans are provided for equipment that may result in an unsafe geometry if improperly loaded.

\section{1 .5 Neutron Absorption}

This control is not applicable to Spray Booth Operations.

\section{1 .6 Concentration}

The maximum uranium concentration of rinse booth solution is explicitly limited to $5 \mathrm{~g} / \mathrm{l}$. Although this is much larger than would be expected in normal situations, the OMs do not specify any procedures to ensure compliance with this limit.

As discussed in Section 4.0, a warning sign on the north end of the tunnel indicates that the concentration of the spray booth solutions is limited to $27.5 \mathrm{~g} / \mathrm{l} 235 \mathrm{U}$. Since this limit is no longer required in any OM or OSR, its status as a control is questionable. In practice, no measurements of the concentration are required or performed regularly. The general belief appears to be that a solution with this much uranium would be ineffective for decontamination and that the solution would have been changed before such concentrations were attained.

The origin of this $27.5 \mathrm{~g} / \mathrm{l}$ limit on the $235 \mathrm{U}$ concentration was traced to NCS documentation from 1956 before its trail was lost. Its basis was the C-12-4 pumps in the acid spray booths. Although neither the nomenclature nor a detailed description of these pumps was documented, it appears that replacement pumps were installed in the 1970s. The only information presented indicates that the volume of the pumps was conservatively estimated to be $4750 \mathrm{ml}$ and the volume of all piping within 15 inches of the pumps was $3950 \mathrm{ml}$. This total volume of $8700 \mathrm{ml}$ was assumed to be a sphere with a radius of $12.76 \mathrm{~cm}$. A concentration limit of $27.5 \mathrm{~g} / \mathrm{l} 235 \mathrm{U}$ then resulted in a safe solid angle of 2.7 steradians. Using the data presented in GAT-22520 (Figure A-6), it 
can be deduced that $k_{\text {eff }}$ for the pumps was estimated to be either $\sim 0.68$ or $\sim 0.82$, depending on whether partially reflected or unreflected systems, respectively, were assumed.

Because of the uncertainty in the history of this concentration limit, an analysis of the current pumps is presented in Appendix B and Appendix C. Based on the analysis of Appendix B, it does not appear as if a concentration limit is necessary for the current (Tri-Clover) C-12-4 pumps, used to pump solution from the citric and nitric acid storage columns to the spray booths. On the other hand, the Wilden M8 pump of the scavenger system is considerably larger than the Tri-Clover pumps. Under the conditions of most-reactive uranium concentration and full reflection by water, the analysis of Appendix $C$ indicates that the Wilden pump is unsafe. Criticality concerns of the Wilden pump are discussed in Sections 6.0 and 7.0.

\section{1 .7 interaction}

Interaction is difficult to analyze in detail without computer simulations. At the time $X-705$ was constructed, the only method for dealing with interaction was solidangle theory.

The original design appears to have been concerned with the interaction among the 5-in. vertical storage columns in the tunnel basement. Each of these pipes is separated by a 12-in. by 12-in. paraffin column. The analysis in Appendix D indicates that these columns are sufficiently subcritical.

This report did not attempt to model the entire spray booth to assess the overall interaction of all the piping. Considering the size of the facility and the uncertainty in detailed drawings, such an effort would be a monumental task. Furthermore, the interaction among the various pipes is obviously affected by the concentration of uranium in the solutions. Although it might be reasonable that a small region would have a concentration high enough to be of concern (i.e., the solution is not thoroughly mixed and homogeneous), it is not very credible that such a high concentration could exist throughout the entire spray booth piping. For example, as noted before in Section 5.1.1.3, even the minimum possible concentration for criticality would require hundreds of kilograms of $235 \mathrm{U}$ to be present.

\subsubsection{Moderation}

This control is also not applicable to Spray Booth Operations.

\subsubsection{Reflection}

This control is also not applicable to Spray Booth Operations. 


\subsection{Administrative Controls}

Based on the discussion in Section 5.1, a consolidated listing of administrative controls applicable to Spray Booth Operations is presented in Table 5.1.

The determination of what constitutes, or does not constitute, an administrative control is often rather subjective. Some procedures are clearly administrative controls, e.g., "Do not exceed a concentration limit of $5 \mathrm{~g} / \mathrm{l}$ of $\mathrm{U}$," while other procedures are merely one of several safe ways to accomplish a given task. Because of the administrative consequences (occurrence reports, etc.) of violating an administrative control, care must be taken to distinguish actual safety procedures from merely safe procedures.

Table 5.1 compares the administrative controls and operating limits of the OSR with those noted in the OMs. Because of the limited use of such controls, the agreement is rather good. A few discrepancies, however, are apparent.

Besides the omission of the $27.5 \mathrm{~g} / \mathrm{l}$ control discussed above, the OSR indicates that equipment will be positioned in the rinse booth in such a manner that solutions will not collect in an unsafe geometry. Although this is certainly an appropriate control, it is even more applicable to the citric and nitric acid spray booths. Clarification could be achieved simply by changing the title of Section 5.3.2.3(10) in the OSR to Tunnel Booths (instead of Tunnel Rinse Booth). The OM procedures, however, are in compliance with the OSR.

The other major difference between the OSR and the OMs is the frequency of the inspections for the tunnel storage columns and basement floor. Apparently the current practice is to inspect every two hours when in operation and every four hours when not in operation. Such procedures, which are within the envelope of the OSR, are supposedly to be incorporated into the next revisions of the OMs, some of which currently require inspection every hour during operation.

\subsection{Safety Systems}

None of the NCS documentation designates any safety system for Spray Booth Operations. As noted earlier, however, two sensors are located in a short vertical section of 5 -in. pipe under the rinse booth, where the horizontal 8-in.drain pipe connects to the 5 -in. horizontal storage. If the rinse water solution reaches the level of a sensor, a warning light is displayed on the operator's control panel and an alarm sounds. (It was not clear whether the sensors are redundant, whether one activates the light and the other the alarm, or whether only one is functional.)

Although an administrative control limits the uranium concentration of the rinse booth storage to $5 \mathrm{~g} / \mathrm{l}$, the OMs do not provide any details on how to assure compliance with this requirement. Under normal conditions, the rinse solution would be very dilute. On the other hand, the rinse booth is also fed from the back-flushing of 


\section{Table 5.1 Administrative Controls for Spray Booth Operations}

\section{Parameter}

Volume

Concentration

Miscellaneous

\section{QSR}

Equipment will be positioned (in the tunnel rinse booth) such that rinse solution will not be collected or retained in unsafe geometries.

Maximum concentration allowed in the rinse booth is 5 grams per liter.

The status of the storage columns and the tunnel floor will be monitored every four hours when in operation.

\section{Other NCS Documentation}

Similar wording, but applied to all booths, not just rinse booth.

Same as OSR*.

Check and log tunnel storage levels and condition of tunnel basement hourly when tunnel is in operation.

Check and log tunnel storage levels and condition of tunnel basement every four hours when tunnel is not in operation.

\footnotetext{
- Does not include the $27.5 \mathrm{~g} / \mathrm{l}$ concentration limit posted.
} 
the filters in the three acid spray booths and by the overflow (if it occurs) from tunnel unmeasured storage. The latter of these is typically solution that has been too contaminated for cleaning (either from the acid spray booths or Group I handtables) and consequently has a uranium concentration that could exceed the prescribed limit. In the event of an overflow from tunnel unmeasured storage (or from back-flushing the filters), these level sensors appear to be the primary means to prevent such solution from reaching an unsafe geometry and should consequently be designated as safety systems, unless alternative methods of control are implemented.

Section 6.0 addresses the Double Contingency Principle as it pertains to overflow protection. 


\subsection{EVALUATION}

This section provides an overall assessment of nuclear criticality safety and comoliance with DOE Orders and accepted MMES practices. Compliance with the Double Contingency principle is evaluated, and scenarios of special concern are addressed. General information on control standards and typical operating parameters of the spray booths are presented first to provide a background for the evaluation.

\subsection{Subcritical Limits}

Table 6.1 illustrates the single-parameter subcritical limits of ANSI/ANS 8.1 that are relevant to Spray Booth Operations. (Since these are single-parameter limits, they apply to uranium of full enrichment.) Obviously, these values would not be appropriate operating limits for process activities. ANSI/ANS 8.1 emphasizes (in bold-face italics) that:

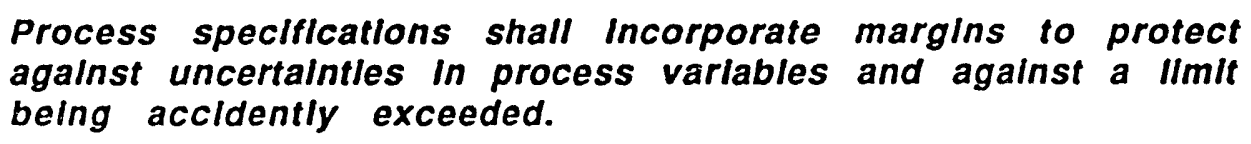

Also shown in Table 6.1 are the corresponding limits prescribed by GAT-225, the PORTS NCS guide. As can be seen, the GAT-225 "individually always-safe" values are more conservative, since they consider double batching, measurement inaccuracies, and other uncertainties of an operational environment. A primary point to be appreciated from Table 6.1 is that single-parameter limits for fully enriched uranium are very small.

Table 6.1 Subcritical Limits of ANSI/ANS 8.1 and GAT-225

$\begin{array}{lcc}\text { Parameter } & \text { ANSI } 8.1 \text { Limit } & \text { GAT-225 Limit } \\ \text { 235U mass } & 760 \mathrm{~g} & 350 \mathrm{~g} \\ \text { Volume } & 5.51 & 4.81 \\ \text { Concentration of } 235 \mathrm{U} & 11.6 \mathrm{~g} / 1 & 5 \mathrm{~g} / 1 \\ \text { Cylinder Diameter } & 13.7 \mathrm{~cm} & 5.0 \mathrm{in} .(12.7 \mathrm{~cm}) \\ \text { Slab Thickness } & 4.4 \mathrm{~cm} & 1.25 \mathrm{in} .^{*}(3.17 \mathrm{~cm})\end{array}$

-May be increased to 1.5 in. $(3.81 \mathrm{~cm})$ if stainless steel construction is used or slab is only half reflected. 
The use of these single-parameter limits often results in an unquantifiable safety margin. During "typical" operation of the spray booths large equipment from various locations of the cascade would require decontamination, and the uranium content of the acid solutions would not be all $235 \mathrm{U}$. Since the equipment contaminated with lowenriched uranium is generally larger and is not as thoroughly cleaned of deposits before entering the spray booths, the assumption of fully enriched uranium could be quite conservative. For example, the ANSI/ANS 8.1 limits of mass, volume, and concentration for a $5 \%$ enriched $\mathrm{UO}_{2} \mathrm{~F}_{2}$ solution are $1,640 \mathrm{~g} 235 \mathrm{U}(\sim 32,800 \mathrm{~g}$ total $\mathrm{U})$, $30.6 \mathrm{I}$, and $261 \mathrm{gU} / \mathrm{l}$, respectively.

It should be noted, however, that this safety margin could be considerably reduced or eliminated during the HEU Suspension Program. If equipment from the upper end of the cascade is processed through the tunnel day-after-day, the solutions will have higher $235 \mathrm{U}$ concentrations.

\title{
6.2 Geometry Control
}

As noted in the discussion of control parameters in Section 5.1, several aspects of Spray Booth Operations currently involve unfavorable geometries. DOE 5480.2421, Section 7a(2), modifies the requirements for geometry control stated in ANSI/ANS 8.1. The Order requires:

\begin{abstract}
4.2.3 Geometry Control. As a first priority, reliance shall be placed on equipment design in which dimensions of the contained fissionable material and spacing between equipment are limited via passive engineering controls. Where geometry control is not feasible, the preferred order of controls is other passive engineering controls, active engineering controls, and administrative controls. Feasibility is determined by weighing risk versus practicality/cost. Full advantage may be taken of any nuclear characteristics of the process materials and equipment. All dimensions, nuclear properties, and other features upon which reliance is placed shall be verified prior to beginning operations, and control shall be exercised to maintain them. The basis for not selecting geometry control shall be fully documented.
\end{abstract}

The use of the word shall in the first sentence, rather than should, is more restrictive than ANSI 8.1, although the consideration of practicality and cost tend to mitigate its mandate.

Compliance with DOE 5480.24 requires either a reconfiguration of these operations or documentation that cost/risk justifies alternative controls. Suggestions are presented in Section 7.0. Because of the relevance of other control parameters (e.g., concentration), the Wilden pump and the volume beneath the rinse booth floor grate are also discussed in Section 6.3 below. 


\subsection{Double Contingency Principle}

As stated in DOE 5480.24, ANSI/ANS 8.1 has been modified to read:

4.2.2 Double centingency Principle. Process designs shall incorporate sufficient factors of safety to require at least two unlikely, independent, and concurrent changes in process conditions before a criticality accident is possible. Protection shall be provided by either (a) the control of two independent process parameters (which is the preferred approach, if practical) or (b) a system of multiple (at least two) controls on a single parameter. In all cases, no single failure shall result in the potential for a criticality accident. The basis for selecting either approach shall be fully documented.

In order to access compliance with the Double Contingency Principle, it is convenient to categorize Spray Booth Operations into three phases:

- Initial dissolving of uranium deposits

- Increase in uranium concentration from continued operations

- Off-normal/accident events

\subsubsection{Initial Dissolving of Uranium Deposits}

This is the initial phase of Spray Booth Operations. It encompasses loading of the equipment onto dollies, movement into the acid booth(s), and the dissolving of the uranium deposits by the acid spray. As discussed in Section 5.1, the only parameter controlled in this phase is volume, and only a single (rather weak) control method is applied-the operator is instructed to assure that solutions cannot collect in an unsafe geometry. No guidance is provided on what constitutes an unsafe geometry for the given enrichment; no loading instructions are available for equipment that is known to have unsafe geometries. Chock blocks and other special fixtures exist for certain types of loads, but the procedures for using them are not documented. It was noted that an Operating Method (RD 2.1) may have r.nce covered loading of equipment, but that $O M$ has not been in effect since at least 1982. As a result, the assurance of a safe geometry is left to one individual, who may or may not be experienced in the relevant issues. From the standpoint of the Double Contingency Principle, at most one "unlikely" event is present.

Section 5.1.3 noted that the mass of potential uranium deposits is often considered in the disassembly of large equipment prior to Spray Booth Operations. Section 7.0 provides recommendations on how to strengthen volume/mass controls to satisfy the Double Contingency Principle for this phase of operations.

\subsubsection{Increase in Uranium Concentration from Continued Operations}

As additional dollies are conveyed through the spray booths, the concentration of the uranium in the acid cleaning solution increases. Concerns frequently arise that 
this concentration might increase to an unsafe level and that the interaction among the numerous pipes might result in a criticality accident.

As was discussed in Section 5.1.6, the Wilden pump for the scavenger system does not appear to be geometrically favorable for all uranium concentrations if it is fully reflected by water. Such a situation could be approximated, for example, by personnel performing routine maintenance on the pump. Furthermore, attempting to place concentration limits on the solution in the scavenger system would be very difficult. This solution collects in a geometrically favorable pipe until it reaches a point at which a level sensor activates the pump and initiates transfer to the unmeasured storage columns. During this collection time, evaporation and/or precipitation could result in a significant increase in concentration above that of the solutions in the acid booth storage. Although one could argue that the likelihood of such a scenario is very low, the scavenger system does not appear to require such a large pump, and the concern could be avoided by merely downsizing the Wilden to a smaller model.

Appendix $D$ analyses the interaction among the 5-in. storage columns in the tunnel basement. Even with very conservative assumptions, these columns appear to be sufficiently subcritical for any uranium concentration, even when the paraffin is removed (as might happen in a fire).

The concentration limit for the rinse booth is a very different issue. Because of the obvious unsafe geometry above the 5 -in. horizontal storage, an administrative control of $5 \mathrm{gU} / \mathrm{l}$ has been established. Furthermore, since the rinse water is eventually transferred to the overhead storage pond, its maximum concentration is, for all practical purposes, $0.5 \mathrm{~g} / \mathrm{l}$. (It is possible, but not straightforward, to move the rinse solution to the nitric acid booth if the concentration is too high for transfer to overhead storage.) Under normal conditions, therefore, the rinse water solution is very dilute, and it is difficult (but perhaps not impossible) to envision a scenario in which the uranium concentration would approach a level of concern. On the other hand, because of the configuration of the overflow system and the limited volume of the rinse booth storage, several off-normal or accident events need to be considered in more detail.

\subsubsection{Off-normal/Accident Events}

As noted earlier, for all practical purposes no concentration limits are currently in effect for the acid cleaning solutions. When the solutions are no longer effective in decontamination, they are pumped to the tunnel unmeasured storage, where they await further transfer to recovery. Consequently, their concentration could well exceed $5 \mathrm{gU} / \mathrm{l}$. Although data of typical concentration limits achieved in the storage columns were very limited, review of several samples from operation in 1992 indicated one value of approximately $15.6 \mathrm{gU} / \mathrm{l}$. (Note that this was total uranium, not 235U; enrichment data were not available. However, if the only equipment being 
decontaminated is from the upper end of the cascade, the difference between $U$ and $235 \mathrm{U}$ could be small.)

A situation of concern involves the attempted transfer of the solution from an acid booth storage to tunnel unmeasured storage, when the latter is already filled. Such a transfer could result from a faulty gauge (indicating that tunnel unmeasured storage was empty) or perhaps just an inattentive operator. The acid solution would overflow into the rinse booth and reach the level of the alarm sensor(s) in the vertical section of 5 -in. pipe in the tunnel basement. If these sensor(s) did not function, the unfavorable geometry in the rinse booth would begin to fill-potentially resulting in a criticality accident. From the standpoint of the Double Contingency Principle, this scenario involves perhaps no "unlikely" events and certainly not two."

Other scenarios could also result in the overflow of tunnel unmeasured storage. For example, in the event of a problem with the B-38 measuring system, personnel in the recovery area might attempt to return solution to the tunnel unmeasured storage, assuming it was still empty (when in fact it had been filled). As before, a potential criticality situation exists without two "unlikely" events.

An interesting situation arises in the hypothetical case that the two level sensors are redundant and properly qualified as safety systems. Assuming that they did sound an alarm indicating the onset of flooding into the rinse booth, the operator would still be required to stop the transfer manually. Unless his failure to do so can be considered "unlikely" (and it probably cannot be), the sensors would somehow automatically have to prevent any further transfer of solution to unmeasured storage (and hence to the rinse booth) in order to (possibly) satisfy the Double Contingency Principle.

One additional scenario on the unfavorable geometry in the rinse booth should be mentioned. The rinse solution drains into the 8-in. drain pipe through only two inlets, both covered by screens. If these screens become clogged, operating the rinse booth in the recycle mode (or overflow from unmeasured storage) would result in solution accumulating in an unfavorable geometry without encountering the level sensors. One of the two drain screens is rather inconvenient to inspect and.clean. During a walkdown of the tunnel a significant amount of debris was noted on the more accessible screen.

\footnotetext{
- Because the sensors have not been designated as safety systems, they are not subjected to the level of quality assurance, configuration control, maintenance, testing, etc., necessary to ensure that they function properly. In addition, the functioning of these sensors is not essential for normal operations, so their performance does not need to be demonstrated on a regular basis. Therefore, failure of these sensors to operate cannot be considered an "unlikely" event.
} 


\subsection{Outdated Documentation}

Although several of the OMs on Spray Booth Operations have been revised recently, the revisions have not addressed all the changes in hardware implemented over the last 10 years. Of most concern is the reconfiguration of storage in the tunnel basement. RD 2.4 still indicates that the northern-most storage is for contaminated acid (it is now raffinate) and that the two southern-most storage sections are combined (they are now separated into measured and unmeasured storage). In addition, the changes in the storage configurations resulted in significant modifications to the piping connections, which are also not properly documented.

Except for the rinse booth discussed earlier, no potential situations were identified that could result in transfer of fissile solution into an unfavorable geometry within the spray booth itself. However, the raffinate solutions from the tunnel basement storage are transferred to an unfavorable geometry in the heavy metals precipitation area during Recovery Operations.

Although the existence of misleading documentation is an overall unsafe practice, it is not clear that any criticality accident would be imminent because of confusion over these storages. For example, even if the operator transferred contaminated acid solution from the citric booth to north raffinate storage (assuming the latter was for acid storage as indicated in the OM), this solution is apparently sampled twice before transfer to the geometrically unfavorable heavy metals precipitation area. The Double Contingency Principle still appears to be satisfied, but a final determination will require a careful analysis of raffinate processing in future work. (One must ensure, for example, that a transfer of contaminated acid to the raffinate storage does not occur after the samples are taken but before the solution is transferred to the heavy metals precipitation area.)

One additional concern over the raffinate storage should be noted for further analysis during evaluation of Recovery Operations. Although the raffinate is normally expected to be a dilute aqueous solution, the potential for organic solvents (from the extraction process) in the raffinate should be examined. Such solvents can result in high concentrations of uranium. If the raffinate solution is not uniform at the time of sampling, or if the solutions could separate after sampling, a potentially dangerous condition could result during Recovery Operations. 


\subsection{RECOMMENDATIONS}

A number of instances were identified in Sections 5.0 and 6.0 for which Spray Booth Operations are not in full compliance with DOE Orders and MMES standard practices. This section summarizes that identification and provides suggestions for alternative actions.

\subsection{Geometry Control}

The unfavorable geometry of the rinse booth floor and storage needs to be addressed. Reconfiguration of this system would be a major task, and an ideal, but simple, solution is not obvious. This subject is further addressed in Section 7.2.3 below.

The Wilden M8 pump for the scavenger system is apparently larger than required for its function. The criticality concerns with this pump could be eliminated simply by replacing it with a smaller model thas is geometrically favorable for all uranium concentrations.

The basement fleor of the tunnel requires maintenance. After the cause of the current pools is determined and corrected, the floor should be cleaned and repaired as necessary.

The issues associated with the electrical boxes and connections with air/water lines are common to many areas in X-705 (and probably other buildings at PORTS). It is suggested that standard policies be implemented by MMES and action be initiated to require compliance.

Risks associated with the steam condensate tank are beyond the scope of Spray Booth Operations, since it appears that the main concern is from Uranium Recovery. On the other hand, if the results of evaluation of the recovery area warrant, reconfiguration of this tank to favorable geometry does not appear to be a significant effort.

\subsection{Double Contingency Principle}

\subsubsection{Initial Dissolving of Uranium Depesits}

Operating Methods for Spray Booth Operations (and perháps also for Large Parts Disassembly and South Annex) should be revised to incorporate more stringent requirements for volume control and mass reduction. Especially with HEU, the only effective criticality control at this point in the operation is positioning the equipment so that solution cannot collect in an unsafe geometry. It is suggested that at least two personnel assess the safety of the geometry and that standard loading plans for 
equipment also be developed and incorporated into spray booth procedures. (In addition to providing a safety function, such plans could be beneficial in training new personnel.) It is further recommended that a mass restriction similar to that noted in DM-868 (no more than a film of material) be instituted.

The Tunnel Shift Report, shown in RD 2.4, provides a record to verify proper cleaning procedures. This report may be appropriate for documenting inspections before equipment can enter the tunnel.

\section{Z2.2 Increase in Uranium Concentration from Continued Operations}

If the Wilden pump is replaced, no concentration concerns appear to exist for normal operations.

\section{Z.2.3 Off-normal/Accident Events}

Although the increase in uranium concentration does not appear to be an issue in the acid booths, the off-normal/accident conditions involving transfer into the rinse booth should be resolved. Modification of the rinse booth to provide a favorable geometry appears to be a major project that would no doubt have significant cost and schedule implications. The largest risk (overflow from unmeasured storage) would appear to be eliminated by routing the overflow to the tunnel floor. Such an approach has obvious drawbacks and may not preclude concerns with blocked drains.

The current situation appears to have developed because changes were instituted to address environmental concerns without a thorough criticality review. The possibility of a quick-fix is not likely. Changes to current procedures require a careful analysis of several options, with input from operational, criticality, and engineering personnel. In addition to present operations associated with the HEU Suspension Program, the longer-term use of the spray booth should be considered. As noted earlier, the controls for LEU are not nearly as stringent.

\subsection{Documentation}

Because of the complexity of operating the spray booth, the documentation (especially Operating Methods) required to support it is extensive. It is not clear that sufficient staff exists in X-705 to satisfy the demands being generated for both operational results and compliance tasks.

Additional resources, if necessary, should be provided to update spray booth documentation. As noted earlier, five OMs currently prescribe procedures for Spray Booth Operations. The appropriateness of combining some of these is a decision that operations personnel are best qualified to resolve. It is suggested, however, that procedures for any given operation be covered in only one $\mathrm{OM}$. If they are repeated in several OMs, the task of assuring that changes to such procedures are incorporated in all documents is difficult, and inconsistencies between two documents often result. 


\subsection{REFERENCES}

1 M.K. Sheaffer and S.C. Keeton, Introduction to the Nuclear Criticality Safety Evaluation of Facility X-705, Portsmouth Gaseous Diffusion Plant, UCRL-ID-114900, Lawrence Livermore National Laboratory, Livermore, CA , August 16, 1993.

2 T.R. Lemons, NCS Evaluation of X-705 Spray Booth Operations, MMES Job Request X-3, DOE Task 33-91-15, October, 5, 1992.

3 GAT/GDP-1073, Portsmouth Gaseous Diffusion Plant Final Safety Analysis Report, Volume 1-3, April 1985.

4 J.L. Feuerbacher, Nuclear Criticality Safety in the X-705 Decontamination and Recovery, and Related Areas, GAT-DM-868, Rev. 4, Goodyear Atomic Corporation, December 1984.

5 Standard Practice Procedure H-30, Nuclear Criticality Safety, Martin Marietta Energy Systems, Inc., April 16, 1991.

6 Tunnel Rinse Booth Solutions (X-705 Environmental Projects), X-705, Criticality Hazards Facility Change Agreement FCA-356, October 18, 1988.

7 Posting of Administrative Controls and Limits, X-705, Criticality Hazards Facility Change Agreement FCA-305, August 7, 1987.

8 Operational Safety Requirements for X-705 Decontamination Building, GAT/GDP-1074, Part H, Rev. 3, Production Services Department, Portsmouth Gaseous Diffusion Plant, April 22, 1985.

9 J. W. Oyer, Decontamination of Large Parts, RD 2.2, Rev. 1, Operations Division, Chemical Operations, April 8, 1982.

$10 \mathrm{~W}$. Jordan and J. Oyer, Operation of the X-705 Spray Tunnel Dolly Motive System, RD 2.3, Rev. 0, Operations Division, Chemical Operations, July 8, 1981.

11 J.W. Oyer, Operation of the Spray Booths, RD 2.4, Rev. 0, Operations Division, Chemical Operations, October 12, 1982.

12 D. Atkins and W. Jordan, Spray Tunnel Solution Makeup and Adjustment, RD 2.10, Operations Division, Chemical Operations, February 6, 1981.

13 K.E. Bugg, Guideline for Decontamination of Technetium Bearing Equipment, RD 2.2.2, Rev. 1, Operations Division, Chemical Operations, September 24, 1981. 
14 J.M. Woods, Special Handling of Equipment Containing Deposits of Uranium, RD 2.2.1, Rev. 2, Operations Division, Chemical Operations, January 20, 1992.

15 J.W. Oyer, Disassembly and Decontamination of Excessive Uranium or Technetium Bearing Equipment, RD 2.2.3, Rev. 1, Operations Division, Chemical Operations, July 16, 1982.

16 S.O. Gillespie, Handling Equipment Containing Deposits of Uranium, CA-MP 8.3, Rev. 1, Operations Division, Cascade Operations, January 16, 1992.

17 S.O. Gillespie, Classifying Equipment Which Contains Deposits of Uranium, CN 8.3, Rev. 11, Operations Division, Cascade Operations, January 20, 1992.

18 American National Standard for Nuclear Criticality Safety in Operations with Fissionable Materials Outside Reactors, ANSI/ANS 8.1, American Nuclear Society, LaGrange Park, llinois, October 7, 1983.

19 Control and Accountability of Nuclear Material, DOE Order 5633.3, US Department of Energy, June 29, 1990.

20 J. L. Feuerbacher, Nuclear Criticality Safety Guide for the Portsmouth Gaseous Diffusion Plant, GAT-225, Rev. 4, Goodyear Atomic Corporation, March 15, 1981.

21 Nuclear Criticality Safety, DOE Order 5480.24, US Department of Energy, Washington, DC, August 12, 1992. 


\section{APPENDIX A EXISTING NCS DOCUMENTATION}

The following list is a concise summary of NCS dócumentation for the X-705 spray booth operations. Additional information on each document is discussed in Section 4.0 of this report, and bibliographic data are presented in Section 8.0.

ESAB

Sections 4.3.1.3.1.4, 5.3.1.4, 5.3.2.2.1

Development Memes

DM 868, Rev. 4 - pp. 99-100

Eacility Change Agreements

FCA-356

FCA-305 (para. 11, 12)

Qperational Safety Requirements

Sections 2.8, 3.3.3, and 5.3.2.3

Operating Methods and Procedures

RD 2.2, Rev. 1

RD 2.2.1, Rev. 2 (supporting)

RD 2.2.2, Rev. 1

RD 2.2.3, Rev. 1 (supporting)

RD 2.3, Rev. 0

RD 2.4, Rev. 0

RD 2.10, Rev. 0

CA-MP 8.3, Rev. 1 (supporting)

CN 8,3, Rev. 11 (supporting)

\section{Drawings}

$X-705-601-M-Y$

$X-705-602-M-Y$

$X-705-603-M-Y$

$X-705-604-M-Y$

$X-705-605-M-Y$

$X-705-606-M-Y$
Spray Booth Piping at Acid Storage Bays

Spray Booth Piping at Col. No. 12 to Col. No. 13 and Details Spray Booth Piping at Spray Booth

Spray Booth Piping at 1 st Rinse \& Carbonate Storage Bays Spray Booth Piping Details of Storage Tank Connections Spray Booth Piping Measuring Tanks Details, Elevations, \& Sections 
Drawings (continued)

$X-705-607-M-Y$

$X-705-608-M-Y$

$X-705-608.50-M-Y$

$X-705-608.51-M-Y$

$X-705-608.52-M$

$X-705-608.53-M$

$X-705-608.54-M$

$X-705-608.55-M-Y$
Spray Booth Piping Details

Spray Booth Piping Flow Control Diagram

Pipe Tank Drain Installation

Overflow Collection System

Spray Booth Baffle Plates

Air Blast For Upper Dolly Chain

Sample Line for Rinse Spray Booth Drain

Additional Spray Booth Manifolds 


\section{APPENDIX B CRITICALITY CALCULATIONS FOR THE SPRAY BOOTH PUMPS}

The spray booth complex has ten pumps in the tunnel basement. Three Ladish Tri-Clover Model C218MD-256TC pumps (designated as C-12-4A, B, and C on PORTS drawings) transfer acid solutions to the spray heads -or to other storage columns in the basement. Four Ladish Tri-Clover Model C114 pumps (designated as C-12-3A, B, C and D on PORTS drawings) transfer solution from measured, unmeasured, south raffinate, and north raffinate storage, respectively, to recovery or to other columns within the tunnel. A Ladish Tri-Clover Model C216 pump (not shown on PORTS drawings) transfers either north or south raffinate solutions to heavy metals precipitation in uranium recovery. The last two pumps are Wilden Model M8 pumps (also not shown on PORTS drawings). One of these pumps is used to transfer overflow solutions from an acid-storage scavenger system to unmeasured storage, and the other is used to transfer steam pit solutions from A Area to the overhead pond. (The use of this model pump for the steam pit solutions is beyond the scope of Spray Booth Operations and is not specifically addressed in this report.) The Wilden M8 pump is discussed in Appendix C.

This appendix examines $k_{\text {eff }} v s$. uranium concentration for the Tri-Clover Model C218 pump. The other Tri-Clover pump models are smaller in size than Model C218 and should be bounded by these calculations. Each of the three $\mathrm{C} 218$ pumps has a slightly different piping geometry, overflow pan, or pump locations within the pan. The pump designated as C-12-4A in PORTS drawings was chosen for analysis since a larger amount of the inlet and outlet piping was nearer to the pump.

Calculations for solution concentrations from 600 to $1000 \mathrm{~g} / \mathrm{l}$ were performed with a configuration-controlled version 1 of the SCALE/KENO system ${ }^{2}$, using the 27group cross sections processed by BONAMI and NITAWL. Validation calculations 3 supporting this version of SCALE, which were the responsibility of MMES, indicated that the criterion for subcriticality should be that $k_{\text {eff }}+2 \sigma$ is less than 0.95 . The remaining calculations for solution concentrations below $600 \mathrm{~g} / \mathrm{l}$ and above $1000 \mathrm{~g} / \mathrm{l}$ were performed with the SCALE/KENO version for the IBM-PC in order to reduce computer costs. (These calculations are included only to show a general trend and should not be used for criticality safety purposes.) Each simulation utilized 1000 neutrons per generation for 110 generations, with the first 10 generations skipped.

A schematic of the Tri-Clover Model C218MD-256TC pump is shown in Figure B.1. The pump was approximated by two adjacent cylinders. The first cylinder had an internal radius of $13.97 \mathrm{~cm}$ (5.5 in.) and an internal thickness of $4.84 \mathrm{~cm}(1$ $29 / 32$ in.), the second cylinder an internal radius of $6.99 \mathrm{~cm}(2.75 \mathrm{in}$.$) and an internal$ thickness of $4.84 \mathrm{~cm}(129 / 32$ in.). These dimensions are very conservative and represent an internal pump volume significantly larger than that of the actual pump. 
The pump motor was approximated by a 316 stainless steel cylinder with outer diameter of $38.1 \mathrm{~cm}$ (15 in.) and length $76.2 \mathrm{~cm}$ (30 in.). The pump has a $3 \mathrm{in}$. inlet pipe and a 2 in. outlet pipe, which were approximated as 316 stainless steel cylinders with $6.72 \mathrm{~cm}$ and $5.08 \mathrm{~cm}$ internal diameter, respectively. (Although Figure B.1 indicates a vertical outlet stream, an elbow redirects it to be parallel to the inlet pipe.) The remaining piping, pan, and concrete stand were not modeled, as the simulations assumed complete water reflection and interaction with these components would be very small. (In order to verify this assumption, additional calculations using an IBM-PC version of the code were performed in which all piping within about two feet of the pump, the pan, concrete pump support, and concrete floor were included. No differences in $\mathrm{k}_{\text {eff }}$ greater than approximately 0.02 were noted.) The solution in the oump and pipes was assumed to be $\mathrm{UO}_{2} \mathrm{~F}_{2}-\mathrm{H}_{2} \mathrm{O}$, with the uranium enriched to $97 \%$.

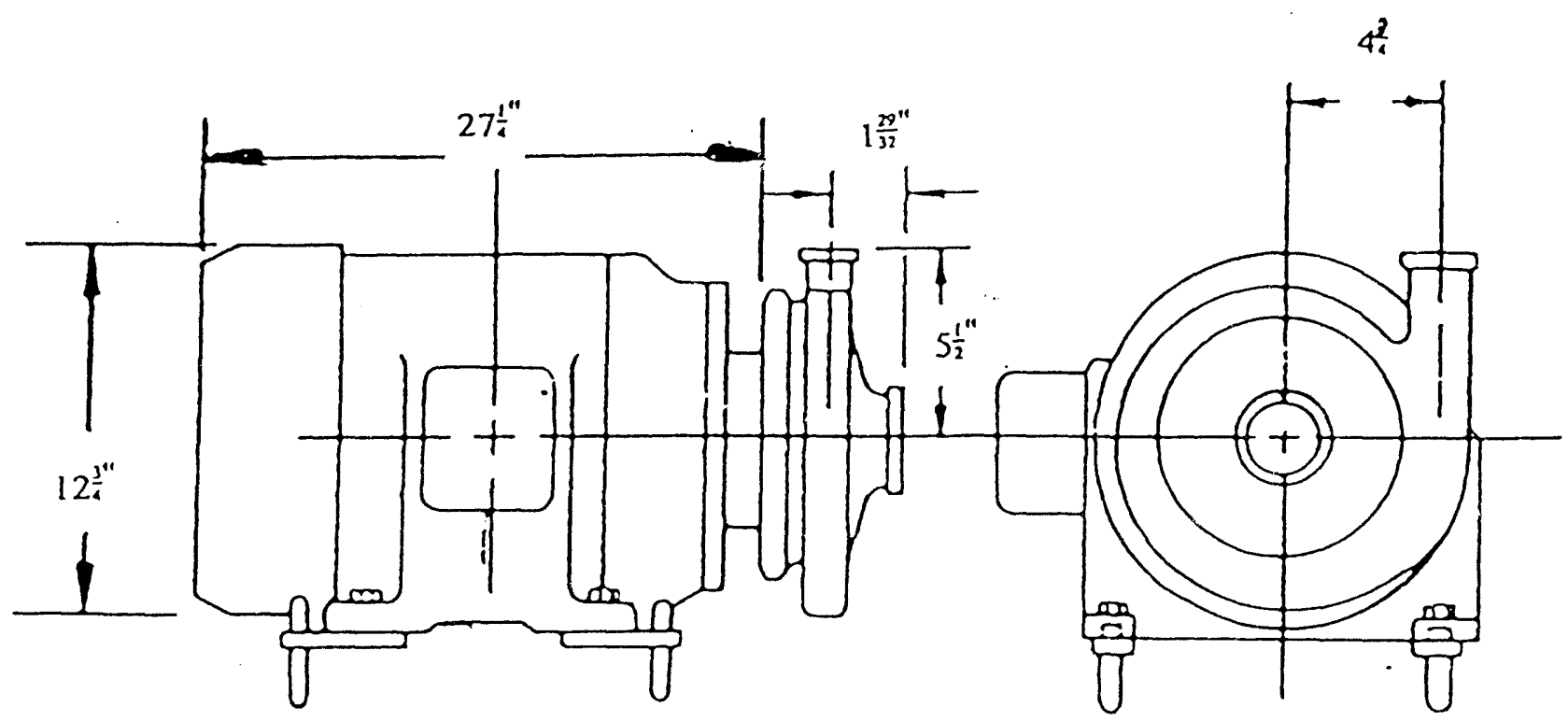

Figure B.1 Ladish Tri-Clover Model C218MD-256TC pump 
A representative computer input is included as Table $B .1$ at the end of this appendix. One uncertainty that always arises for $\mathrm{UO}_{2} \mathrm{~F}_{2}$ solutions is the variation of uranium density with the $H / U$ ratio. As can be seen from the input, the calculations in this appendix (as well as all others in this report) used the default options of KENO. Not only is this choice the most easily reproducible, but it does not appear that any other reasonable option would affect the conclusions presented below.

Figure B.2 shows the $k_{\text {eff }}$ vs. uranium concentration for the Tri-Clover pump. The maximum $k_{e f f}$ is about 0.85 . This value is significantly less than 0.95 and indicates all Tri-Clover pumps in the spray booth should be sufficiently subcritical.

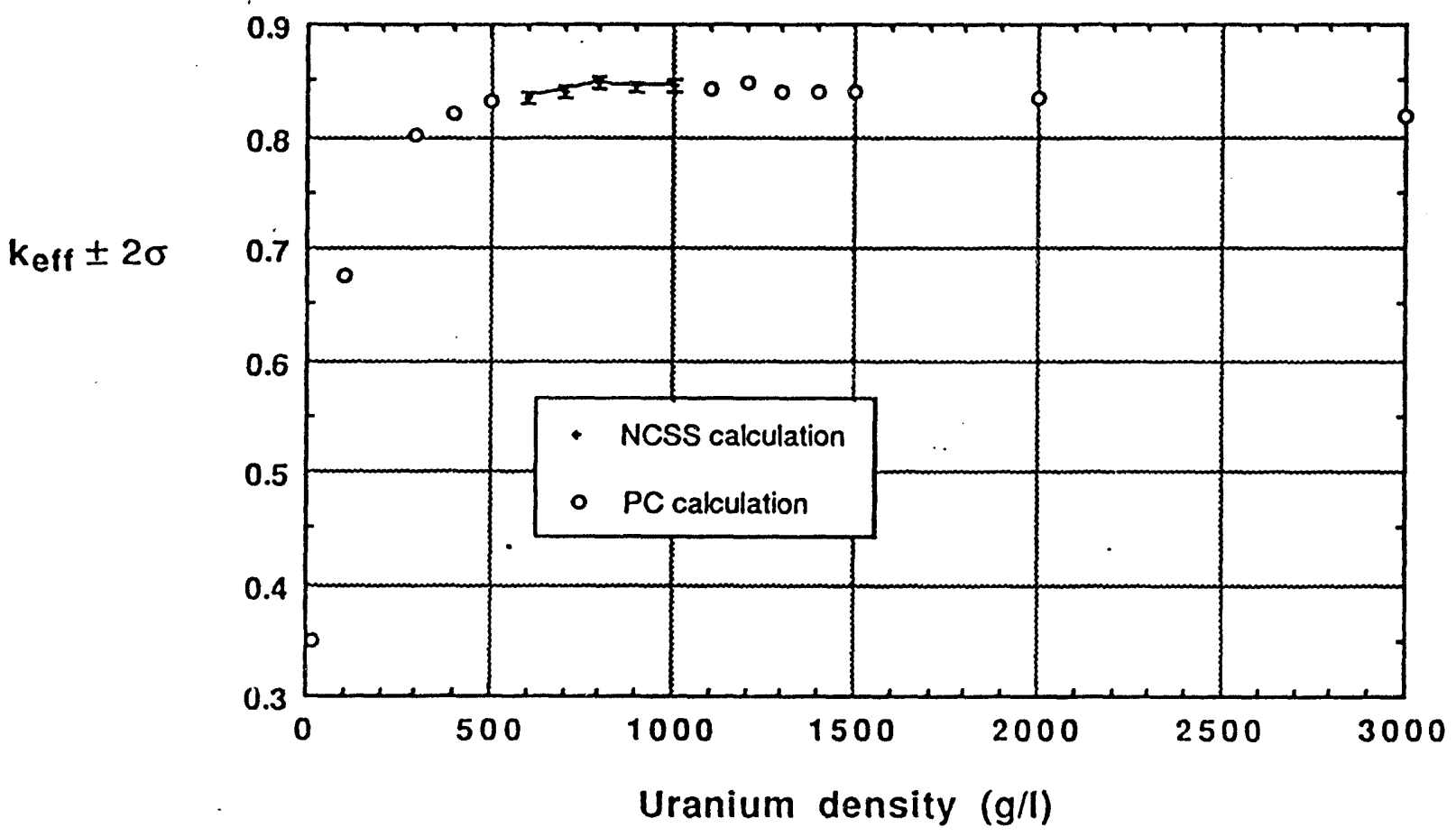

Figure B.2 $\mathrm{k}_{\text {eff }}$ vs. uranium concentration for the Tri-Clover C218 pump 
Table B.1 Typical Input File for Results Shown in Figure B.2.

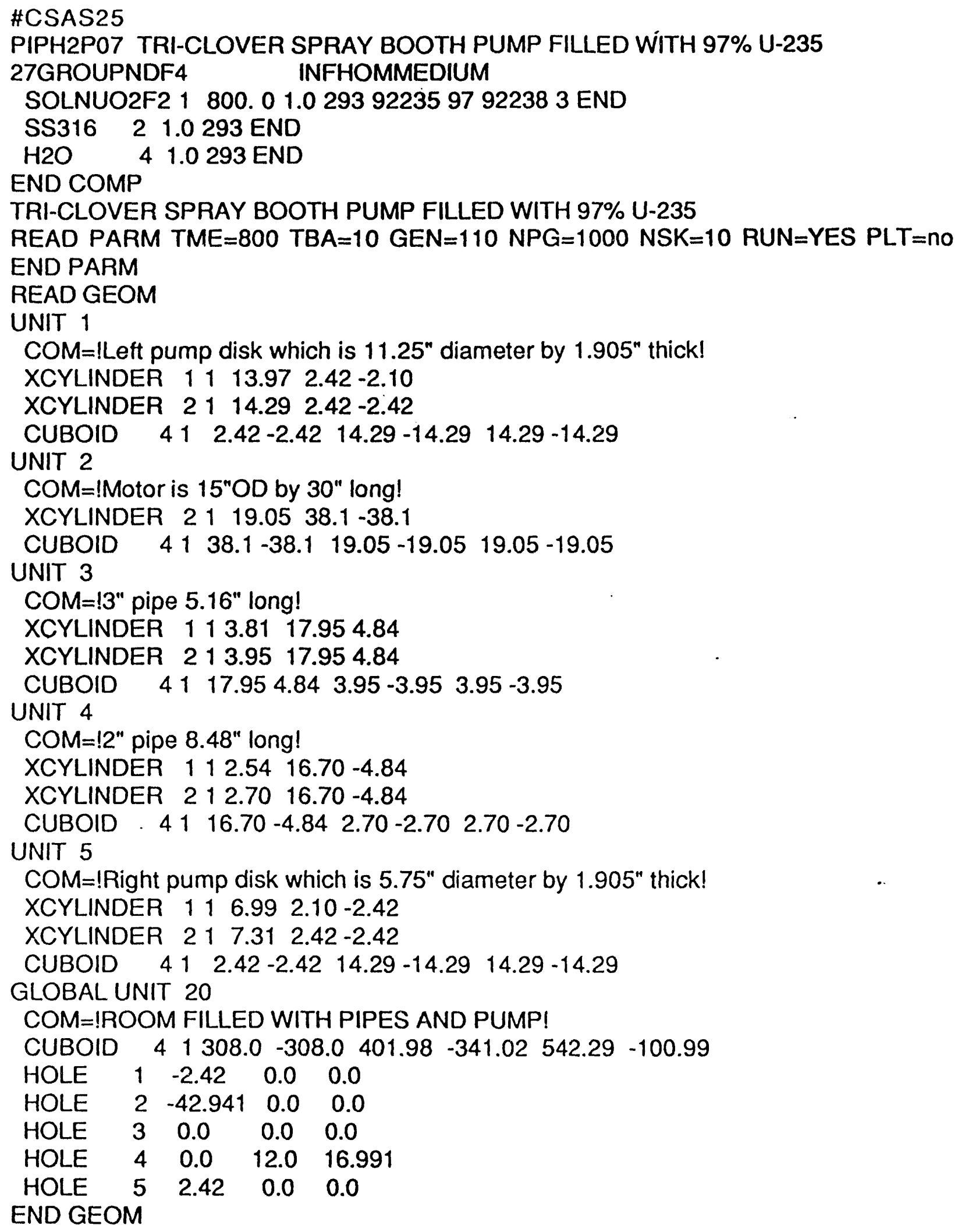


READ START NST $=0$

$X S M=-4.9 \quad X S P=18.0 Y S M=-14.6 \quad Y S P=14.6 \quad Z S M=-14.0 \quad Z S P=19.6 \quad P S P=$ no

END START

READ PLOT

END PLOT

END DATA

END

B-5 
1 Martin Marietta Energy Systems (MMES) Nuclear Criticality Safety Software Control Plan K/ESH-3, December 18, 1991.

2 SCALE: A Modular Code System for Performing Standardized Computer Analyses for Licensing Evaluation, NUREG/CR-0200, Revision 4 (ORNL/NUREG/CSD-2/R4), Volumes I, II, and III., April 1992. Available from Radiation Shielding Center as CCC545.

3 Lee, Billy L. Jr., Validation of Nuclear Criticality Software, KENO V.a., with the 27Group ENDF/B-IV Cross Sections, POEF-T-3636, Portsmouth Gaseous Diffusion Plant, Piketon, $\mathrm{OH}$ (to be published). 


\section{APPENDIX C: CRITICALITY CALCULATIONS FOR THE SCAVENGER PUMP}

This appendix examines $k_{\text {eff }}$ vs. uranium concentration for the Wilden Model M8 pump.

Calculations for solution concentrations from 500 to $1000 \mathrm{~g} / \mathrm{l}$ were performed with a configuration-controlled version ${ }^{1}$ of the SCALE/KENO system ${ }^{2}$, using the 27group cross sections processed by BONAMI and NITAWL. Validation calculations 3 supporting this version of SCALE, which were the responsibility of MMES, indicated that the criterion for subcriticality should be that $k_{\text {eff }}+2 \sigma$ is less than 0.95 . The remaining calculations for solution concentrations below 500 and above $1000 \mathrm{~g} / \mathrm{l}$ were performed with the SCALE/KENO version for the IBM PC in order to reduce computer costs. (These calculations are included only to show a general trend and should not be used for criticality safety purposes.) Each simulation utilized 1000 neutrons per generation for 110 generations, with the first 10 generations skipped.

A representative computer input is included as Table C.1 at the end of this appendix. One uncertainty that always arises for $\mathrm{UO}_{2} \mathrm{~F}_{2}$ solutions is the variation of uranium density with the $H / U$ ratio. As can be seen from the input, the calculations in this appendix (as well as all others in this report) used the default options of KENO. Not only is this choice the most easily reproducible, but it does not appear that any other reasonable option would affect the conclusions presented below.

A schematic of the Witden Model M8 pump is shown in Figure C.1. The actual pump has two joined hemispheres, which are separated by an air valve. A 3-in. pipe passes vertically through each outer hemisphere and is connected to 2-in. inlet and outlet pipes on the bottom and top of the pump, respectively.

In the model used for the computer calculations, this pump was approximated as two sets of joined hemispheres, separated by a small volume of water (reflector). Because of KENO geometry limitations, half of the (stainless steel) valve volume was placed as the cap of each inside hemisphere in order to simulate its reftection characteristics. The intersecting pipes at the outer edge of the each hemisphere were approximated as cuboids. The two horizontal pipe segments were approximated by 316 stainless steel cylinders with $5.65 \mathrm{~cm}$ (2.22 in.) inside diameter with length 38.712 $\mathrm{cm}$ (15.24 in.), and the four vertical pipe segments were approximated by cylinders with 316 stainless steel $7.3 \mathrm{~cm}$ (2.87 in.) inside diameter with length $8.572 \mathrm{~cm}$ (3.375 in.). The entire pump and pipes were filled with $\mathrm{UO}_{2} \mathrm{~F}_{2}-\mathrm{H}_{2} \mathrm{O}$ solution (enriched to $97 \% 235 \mathrm{U}$ ), and the entire system was fully reflected with water.

A significant effort was devoted to model the pump as realistically as possible. Because the available pump drawings did not indicate every dimension and the geometry options in the code itself were limited, several approximations were 


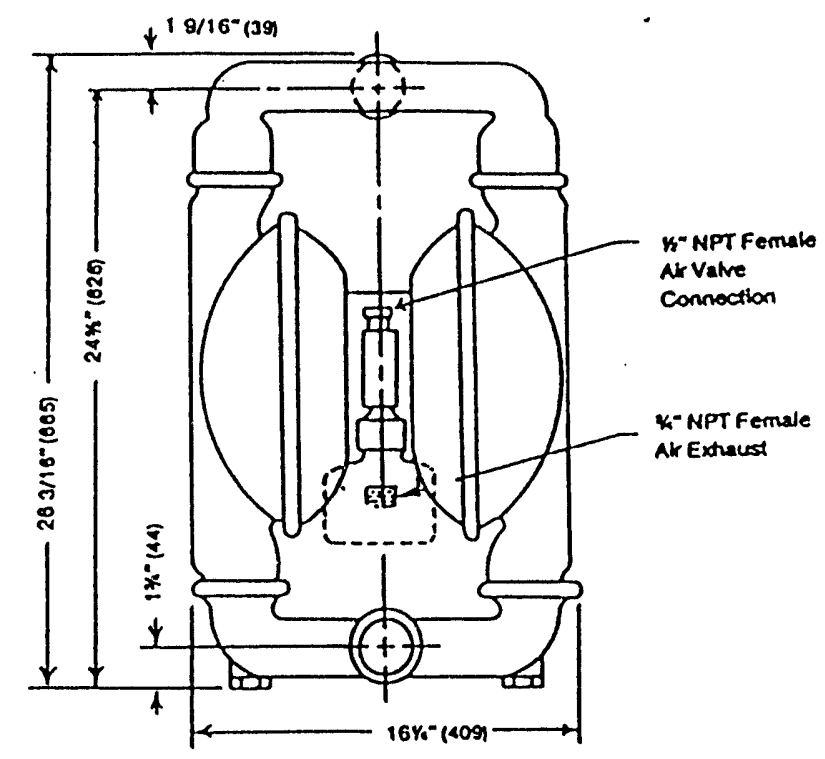

( ) Millimeters

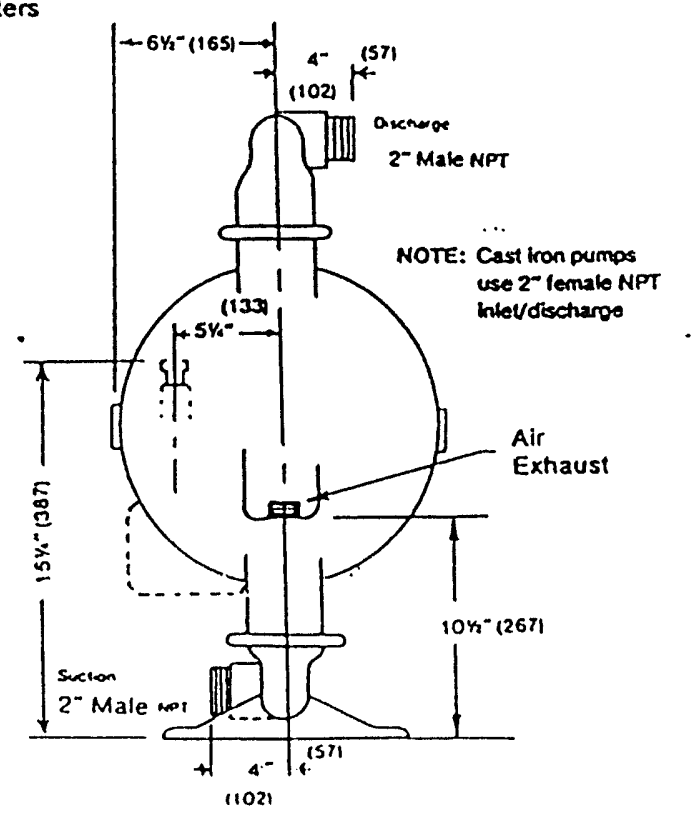

Figure C.1 Wilden Model M8 Pump 
obviously required. Although conservative estimates were sometimes necessary, an attempt was made not to be so conservative that the conclusions from the calculations would be questionable.

Figure C.2 shows the $k_{\text {eff }}$ vs. uranium concentration for the Wilden M8 pump. The maximum $k_{\text {eff }}$ is about 1.05. This value is significantly greater than 0.95 and indicates a criticality concern when the Wilden pump contains a highly concentrated solution and is fully reflected by water. As discussed in the main report, the criticality concern with this pump is probably most easily corrected by replacing the M8 with a smaller model.

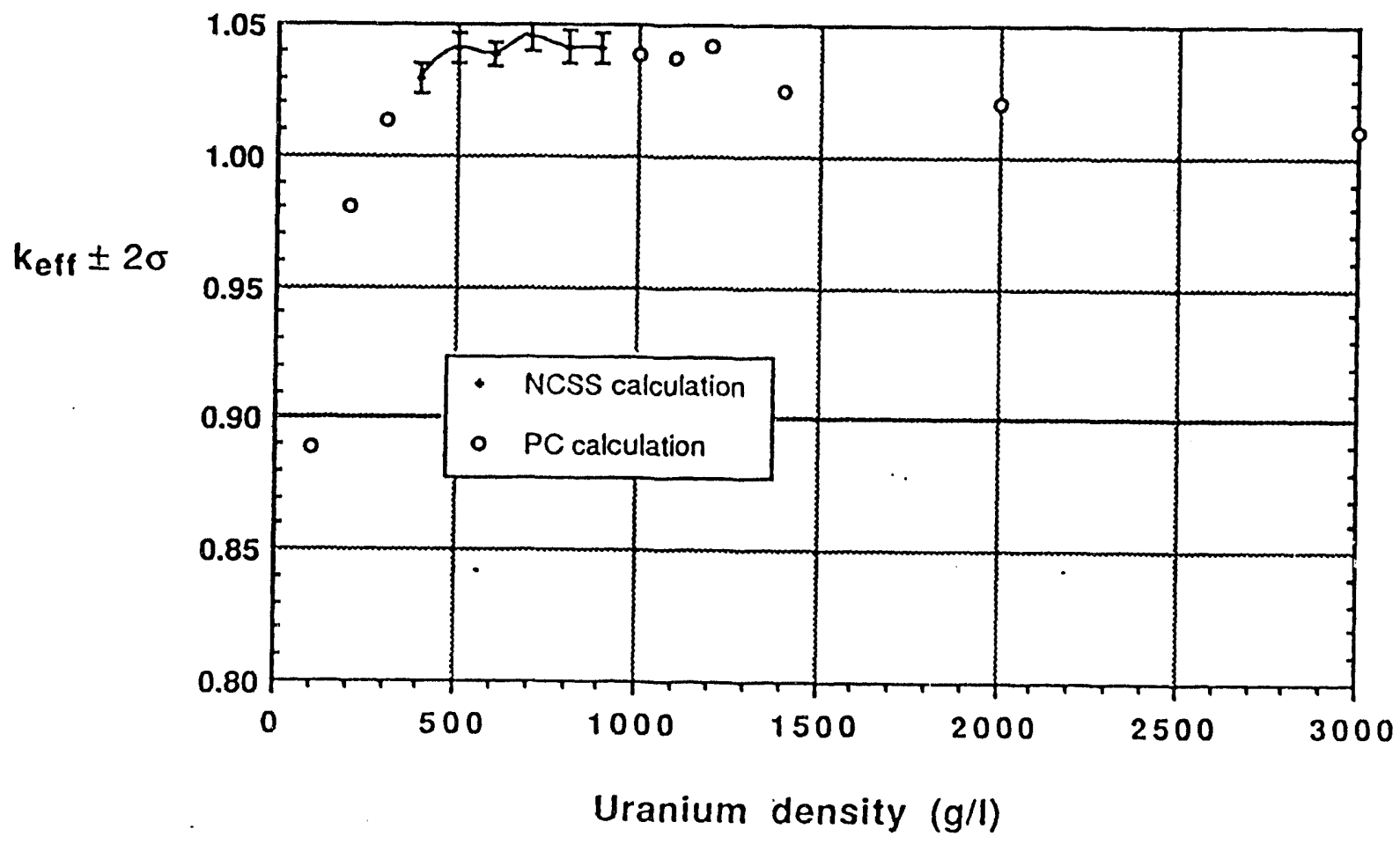

Figure C. $2 k_{\text {eff }}$ vs. Uranium concentration for the Wilden M8 pump 
During the early stages of the evaluation of Spray Booth Operations, the Wilden pump (with its nearby piping) was briefly examined as unreflected. Because PORTS policy is to consider all equipment as fully reflected unless otherwise specified4, further examination of the unreflected configuration was not pursued. Nevertheless, it is worth noting that during normal operation the neutron leakage from the pump and piping is significant. Even with the optimum uranium concentration, conservative pump geometry, interaction with solution in nearby piping and overflow pan, and reflection from nearby concrete, the maximum $k_{\text {eff }}$ for the Wilden pump was approximately 0.87 . The reader is cautioned that this information should be treated as preliminary and does not change the conclusions or recommendations presented in this report. 
Table C.1 Typical input file for results shown in Figure C.2.

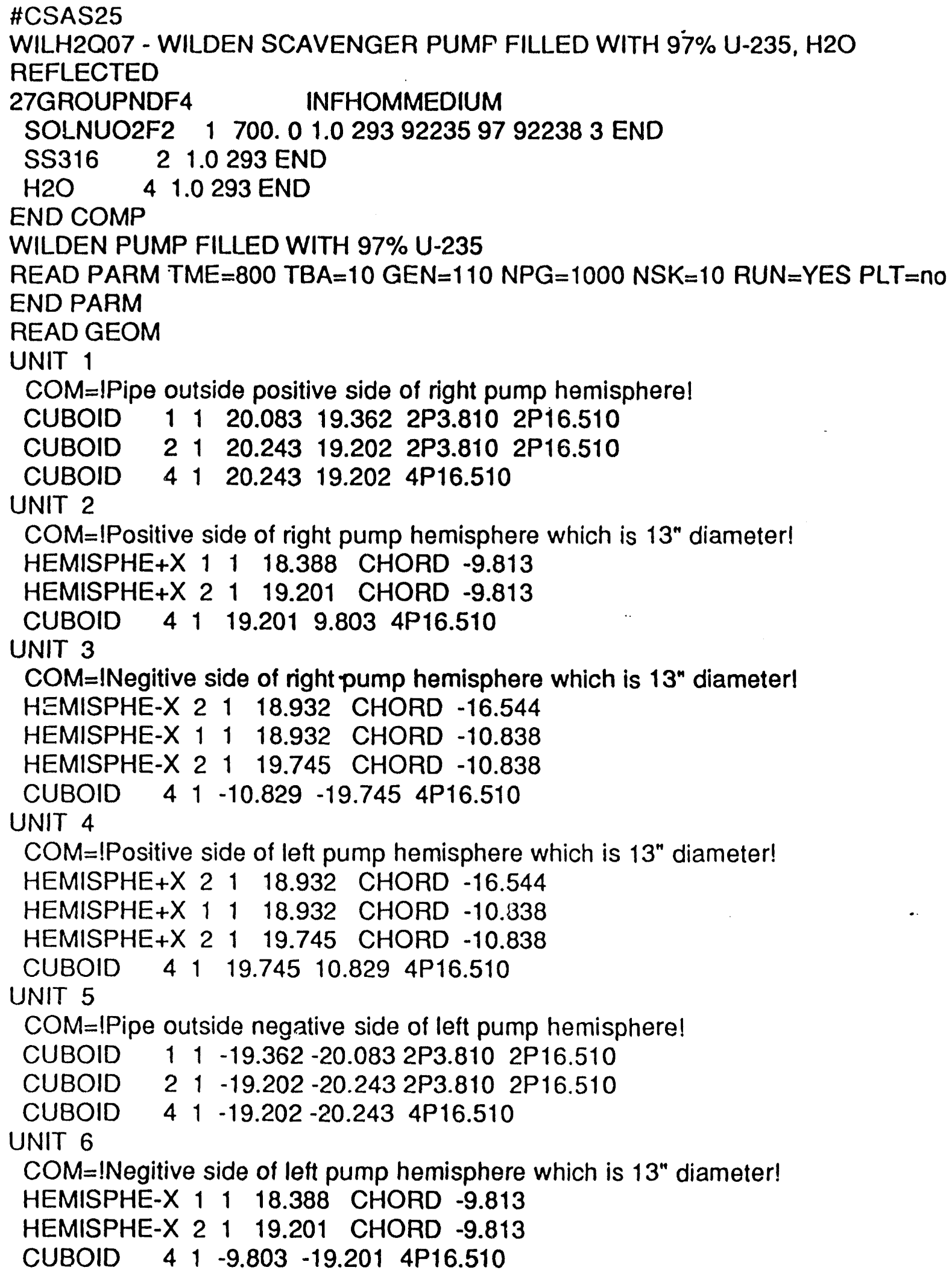

END COMP

WILDEN PUMP FILLED WITH 97\% U-235

READ PARM TME $=800$ TBA $=10$ GEN=110 NPG=1000 NSK=10 RUN=YES PLT=no

END PARM

READ GEOM

UNIT 1

COM=IPipe outside positive side of right pump hemisphere!

$\begin{array}{llllllll}\text { CUBOID } & 1 & 1 & 20.083 & 19.362 & 2 P 3.810 & 2 P 16.510\end{array}$

$\begin{array}{llllllll}\text { CUBOID } & 2 & 1 & 20.243 & 19.202 & 2 \mathrm{P} 3.810 & \text { 2P16.510 }\end{array}$

CUBOID $\quad 4 \quad 1 \quad 20.243 \quad 19.202 \quad 4 P 16.510$

UNIT 2

COM $=$ !Positive side of right pump hemisphere which is $13^{\text {" }}$ diameter!

HEMISPHE $+X \quad 1 \quad 1 \quad 18.388$ CHORD -9.813

HEMISPHE $+X \quad 2 \quad 1 \quad 19.201 \quad$ CHORD -9.813

CUBOID $\quad 4 \quad 1 \quad 19.2019 .803 \quad 4 P 16.510$

UNIT 3

COM $=$ !Negitive side of right pump hemisphere which is $13^{\text {" }}$ diameter!

HEMISPHE-X $2 \quad 1 \quad 18.932$ CHORD -16.544

HEMISPHE-X 11118.932 CHORD -10.838

HEMISPHE-X 2119.745 CHORD -10.838

$\begin{array}{lllllll}\text { CUBOID } \quad 4 & 1 & -10.829 & -19.745 & \text { 4P } 16.510\end{array}$

UNIT 4

COM $=$ !Positive side of left pump hemisphere which is $13^{\text {" }}$ diameter!

HEMISPHE +X $2 \quad 1 \quad 18.932$ CHORD -16.544

HEMISPHE +X 11118.932 CHORD -10.338

HEMISPHE +X 21119.745 CHORD -10.838

CUBOID $\quad 4 \quad 1 \quad 19.745 \quad 10.829 \quad 4 \mathrm{P} 16.510$

UNIT 5

COM $=$ IPipe outside negative side of left pump hemisphere!

CUBOID $\quad 1 \quad 1 \quad-19.362-20.083$ 2P3.810 2P16.510

CUBOID $\quad 2 \quad 1-19.202-20.243$ 2P3.810 2P16.510

CUBOID $\quad 4 \quad 1 \quad-19.202-20.243 \quad 4 P 16.510$

UNIT 6

COM $=$ !Negitive side of left pump hemisphere which is $13^{\text {" }}$ diameter!

HEMISPHE-X $\begin{array}{llllll}1 & 1 & 18.388 & \text { CHORD } & -9.813\end{array}$

HEMISPHE-X $2 \quad 1 \quad 19.201 \quad$ CHORD -9.813

$\begin{array}{llllll}\text { CUBOID } \quad 4 & 1 & -9.803 & -19.201 & 4 \mathrm{P} 16.510\end{array}$ 


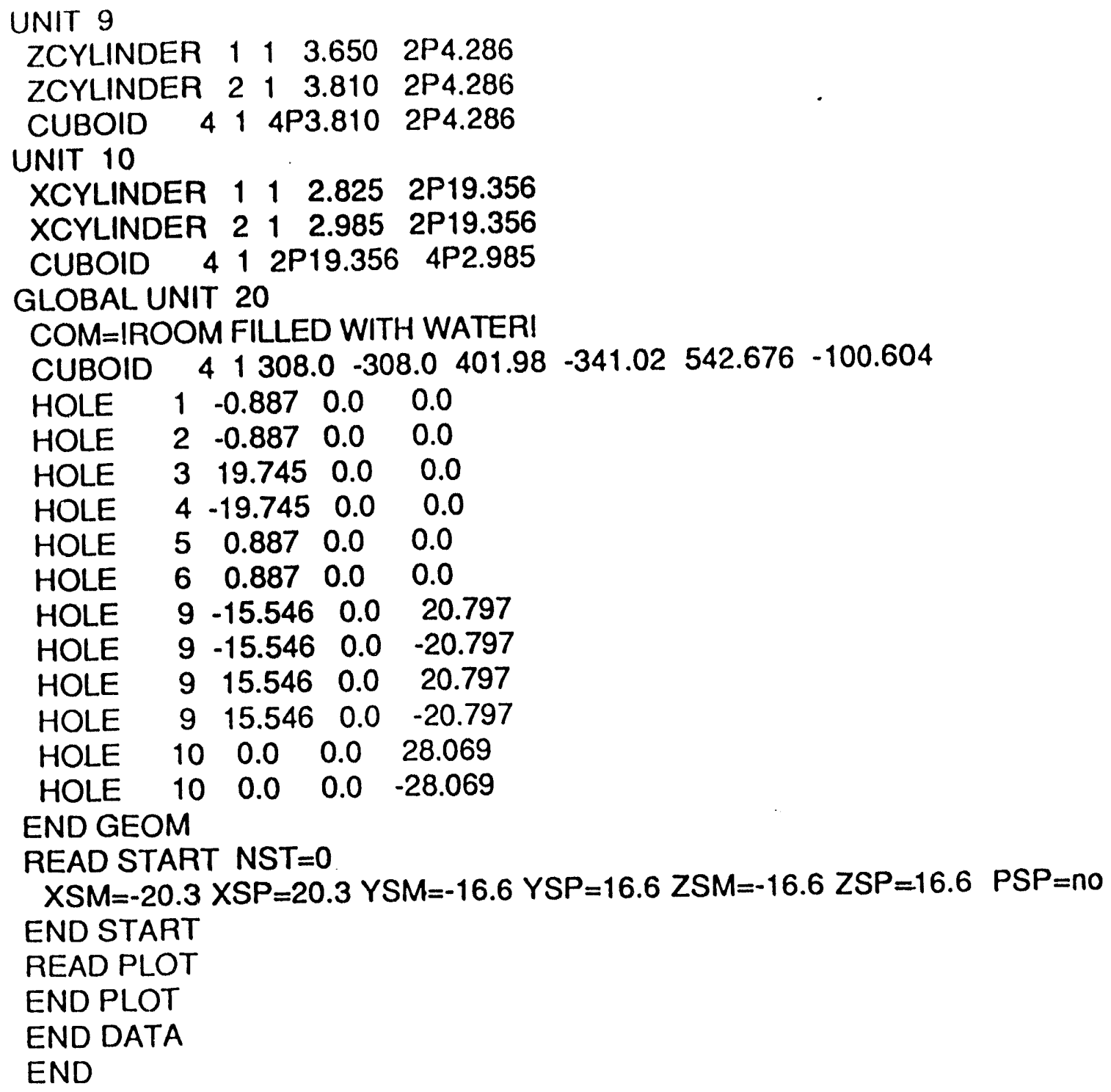


1 Martin Marietta Energy Systems (MMES) Nuclear Criticality Safety Software Control Plan K/ESH-3, December 18, 1991.

2 SCALE: A Modular Code Sysiem for Performing Standardized Computer Analyses for Licensing Evaluation, NUREG/CR-0200, Revision 4 (ORNL/NUREG/CSD-2/R4), Volumes I, II, and III, April 1992. Available from Radiation Shielding Center as CCC545.

3 Lee, Billy L. Jr., Validation of Nuclear Criticality Software, KENO V.a., with the 27 Group ENDF/B-IV Cross Sections, POEF-T-3636, Portsmouth Gaseous Diffusion Plant, Piketon, $\mathrm{OH}$ (to be published).

4 J.L. Feuerbacher, Nuclear Criticality Safety Guide for the Portsmouth Gaseeous Diffusion Plant, GAT-225, Rev. 4, Goodyear Atomic Corporation, March 15, 1981 (p. 22). 


\section{APPENDIX D CRITICALITY CALCULATIONS FOR THE ACID STORAGE COLUMNS}

This appendix examines $k_{e f f}$ vs. uranium concentration for the contaminated acid storage columns in the tunnel basement. The analysis assumes that the solution in the columns is fully enriched $\mathrm{UO}_{2} \mathrm{~F}_{2}-\mathrm{H}_{2} \mathrm{O}(100 \% 235 \mathrm{U})$.

A schematic of the geometry modeled in this analysis is illustrated in Figure D.1. Located on $18.75-\mathrm{in}$. $(47.625-\mathrm{cm})$ centers, the storage columns were considered to be 5 -in. Type 316 stainless-steel schedule-40 pipes with an outside diameter of 5.563 in. $(14.13002 \mathrm{~cm})$. To account for tolerance limits and corrosion of the pipe walls, the inside diameter was increased to $5.150 \mathrm{in}$. $(13.081 \mathrm{~cm})$. Each storage column was separated by $30 \mathrm{~cm}$ of paraffin. (The thin metallic shell supporting the paraffin was ignored.) The wall of the tunnel basement was modeled as $30-\mathrm{cm}$ concrete, and a $30-\mathrm{cm}$ water reflector was placed in front of one column to simulate a man standing on the basement walkway. (Oak Ridge concrete was chosen because in the author's personal experience it has often resulted in a small, but insignificant, increase in reactivity. The mirror boundary conditions shown in the figure resulted in an infinite array along the north-south axis; mirror boundaries were also used to simulate infinite (length) cylinders.

Calculations were performed with a configuration-controlled version 1 of the SCALE/KENO system 2 , using the 27-group cross sections processed by BONAMI and NITAWL. Validation calculations ${ }^{3}$ supporting this version of SCALE, which were the responsibility of MMES, indicated that the criterion for subcriticality should be that $k_{\text {eff }}+2 \sigma$ is less than 0.95 . Each simulation utilized 1000 neutrons per generation for 110 generations, with the first-10 generations skipped.

A representative computer input is included as Table D.1 at the end of this appendix. One uncertainty that always arises for $\mathrm{UO}_{2} \mathrm{~F}_{2}$ solutions is the variation of uranium density with the $\mathrm{H} / \mathrm{U}$ ratio. As can be seen from the input, the calculations in this appendix (as well as all others in this report) used the default options of KENO. Not only is this choice the most easily reproducible, but it does not appear thät any other reasonable option would affect the conclusions presented below.

Figure D.2 shows the results of the computer calculations for $k_{\text {eff }}$ as a function of the uranium concentration. As can be seen, a broad maximum of $k_{\text {eff }}(\sim 0.83)$ occurs at a concentration of $\sim 800 \mathrm{~g} / / 235 \mathrm{U}$. In order to assess the interaction (or lack of interaction) due to the paraffin, the calculations were repeated with various densities of paraffin separating the columns. These scenarios might be representative of a fire, which melts and releases paraffin from the columns. Figure D.3 illustrates $k_{\text {eff }}$ as a function of paraffin density for a uranium concentration of $800 \mathrm{~g} / \mathrm{l}$. Although a small increase in reactivity is apparent at somewhat less than full density paraffin, the configuration appears to be sufficiently subcritical.

$$
\text { D-1 }
$$




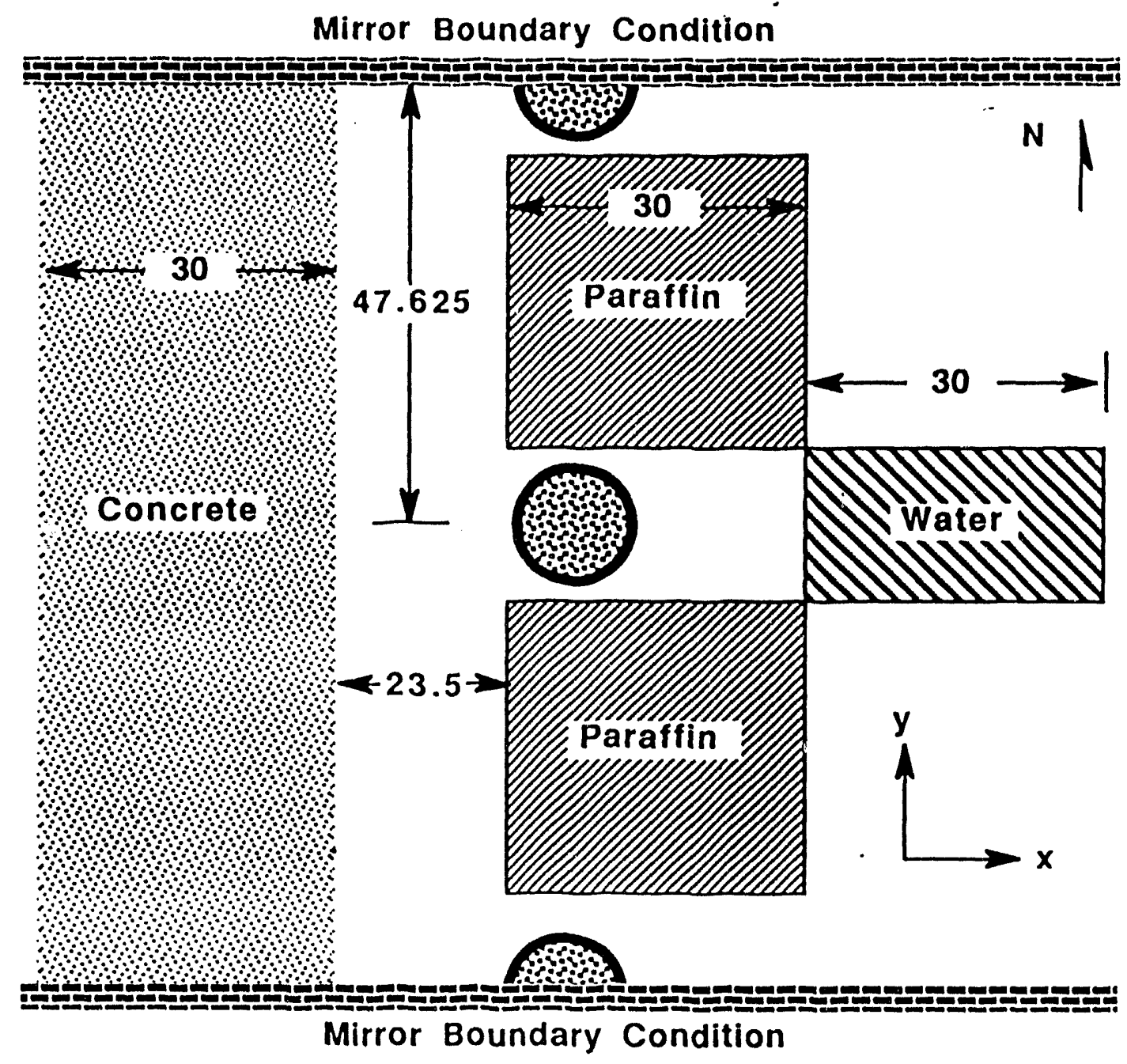

Notes: (1) Storage columns are 5 -In. SS316 Sch 40 pipe $O D=5.563 \mathrm{ln} .(14.13002 \mathrm{~cm})$ ID $=5.150 \mathrm{in} .(13.081 \mathrm{~cm})$

(2) Unless otherwise noted, all dimensions are in $\mathrm{cm}$.

Figure D.1 Schematic of 5 -in. storage columns (top view) 


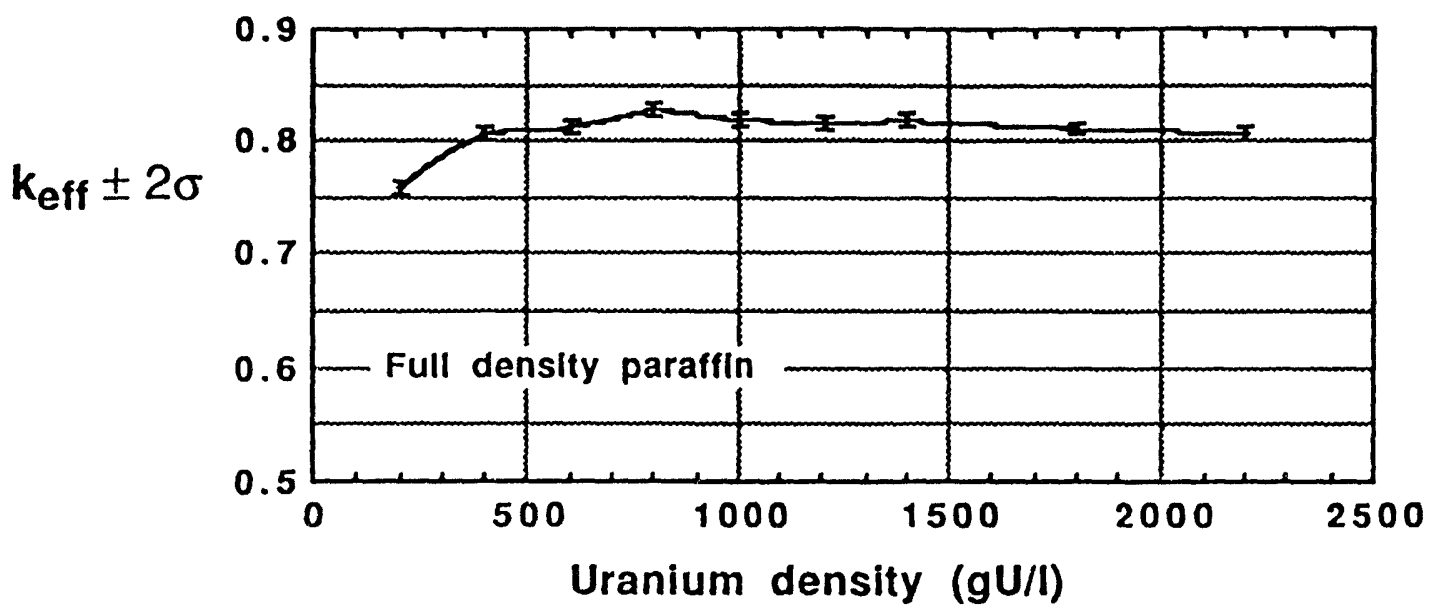

Figure D.2 Variation in $k_{e f f}$ as a function of uranium concentration for full density paraffin

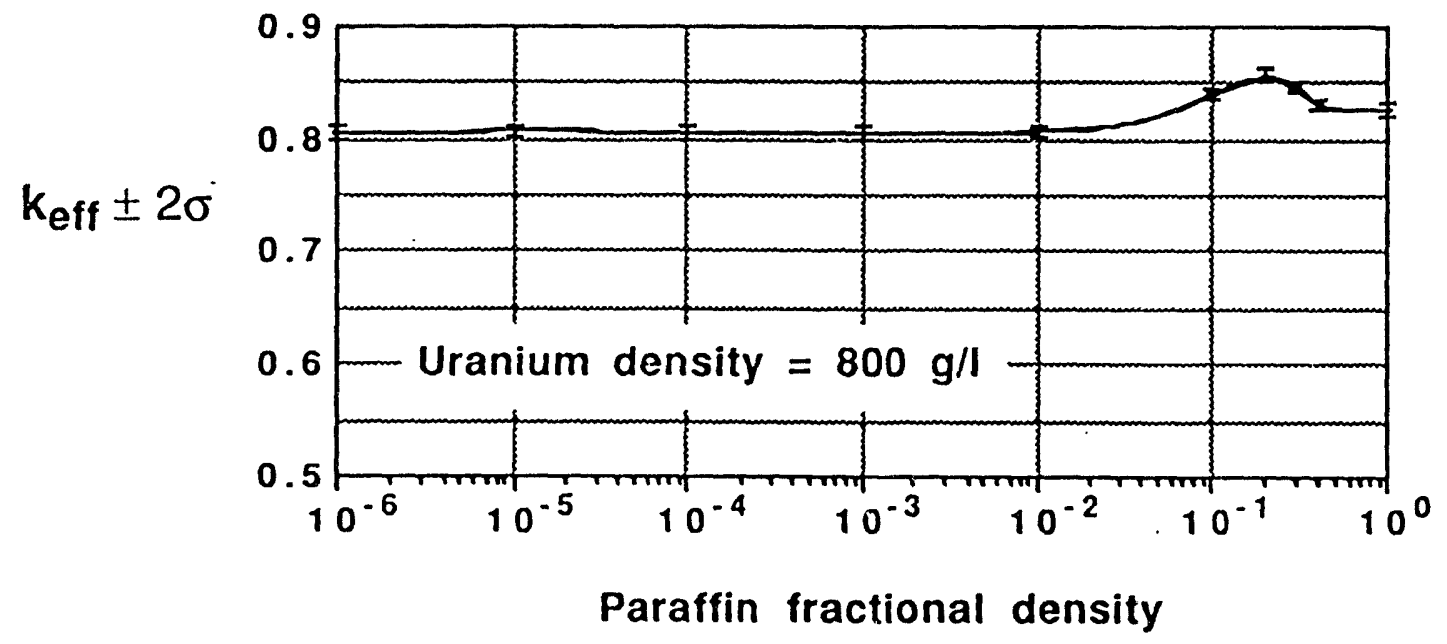

Figure D.3 Variation in $k_{e f f}$ as a function of paraffin density for a uranium concentration of $800 \mathrm{~g} / \mathrm{l}$

D-3 
It should be noted that these calculations have ignored the storage columns on the opposite side of the basement. Because these columns are approximately 20 feet away, it was anticipated that their effect would be small. In order to verify this assumption, several additional calculations were performed with an IBM PC version of the SCALE/KENO code. These calculations examined the base case of Figure D.1 with: (1) no water reflector, (2) no water reflector and a mirror boundary condition 30 $\mathrm{cm}$ from the paraffin, and (3) no water reflector and a mirror boundary condition 240 $\mathrm{cm}(\sim 8 \mathrm{ft}$.) from the paraffin (at the approximate basement centerline). Because the $y$ and $z$-dimensions are infinite, the latter two calculations resulted in essentially the same multiplication factor, which was about 0.05 higher than the base case shown in Figure D.1. Although this is an over-estimate of the interaction (because of the infinite dimensions), the results are still within the subcriticality criterion.

It should also be noted that the conditions modeled in Figure $D .1$ and their variations are very conservative and unrealistic. A concentration of $800 \mathrm{~g} / \mathrm{l}$ of $235 \mathrm{U}$ in each column would imply that approximately $1280 \mathrm{~kg}$ of $235 \mathrm{U}$ were contained in each of the five acid-storage banks of the tunnel basement $(6400 \mathrm{~kg}$ total). (Each bank of 28 columns typically contains about 1600 liters during operation).

A more reasonable scenario would appear to be a very high concentration in one column (or a section of one column), which is also "fully reflected" by maintenance or operational personnel. Since this situation is essentially a single-parameter limit (cylinder diameter) from Table 6.1 , one would expect $\cdot k_{\text {eff }}$ to be slightly greater than 0.9 . As a result, the array appears to be just as subcritical as a single, fully reflected column. 
Table D.1 Typical Input File for Results Shown in Figure D.2

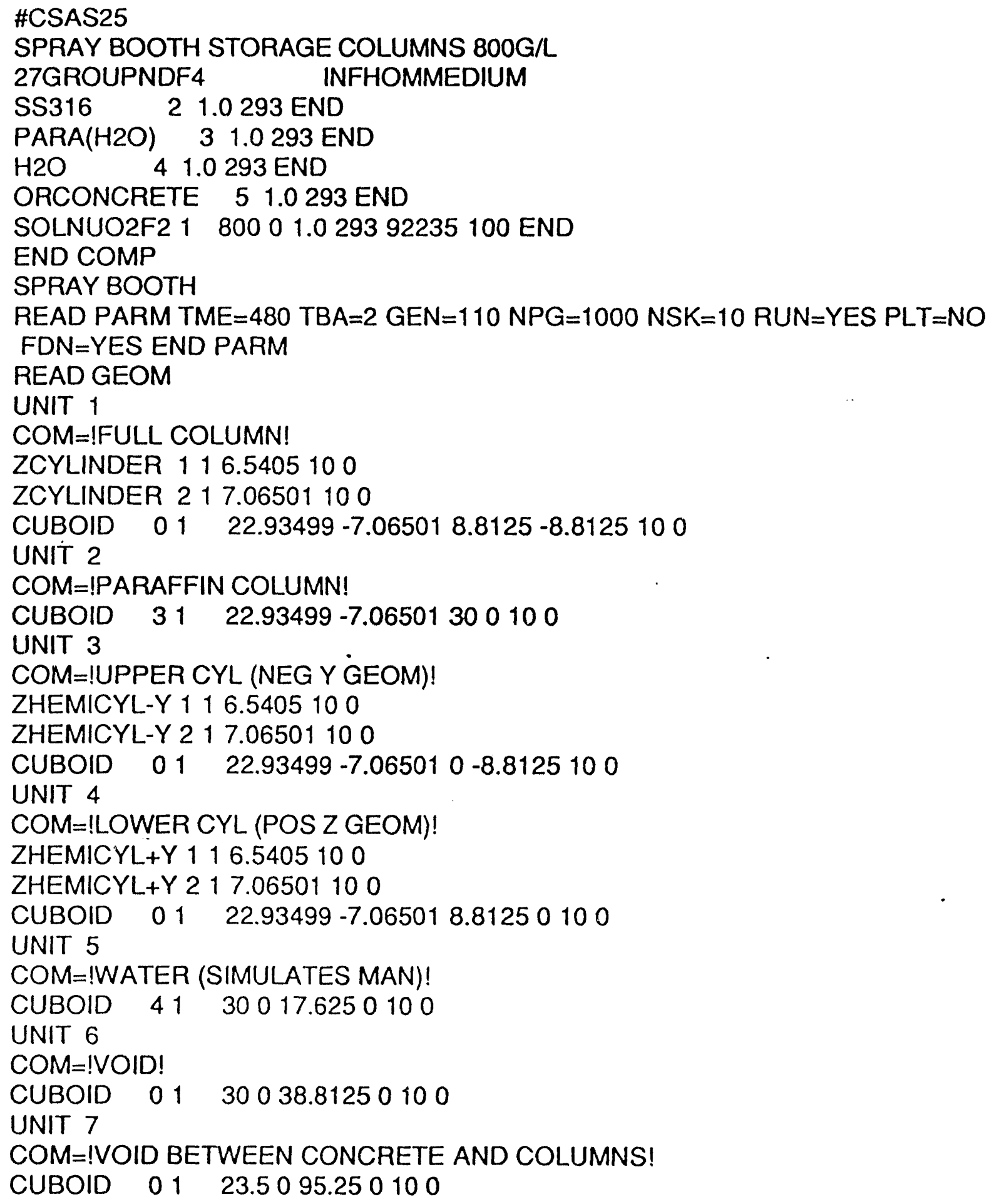


UNIT 8

COM $=$ !CONCRETE WALLI

CUBOID $51 \quad 30095.250100$

UNIT 9

COM=!COLUMNS!

ARRAY 1000

UNIT 10

COM $=$ !REFLECTOR ARRAY!

ARRAY 2000

END GEOM

READ ARRAY

$A R A=1$ NUX $=1$ NUY $=5 \quad N U Z=1$

COM=!ARRAY OF STORAGE COLUMNS!

FILL 42123 END FILL

$A R A=2 N U X=1 \quad N U Y=3 \quad N U Z=1$

COM=!AIR AND MAN REFLECTOR!

FILL 656 END FILL

$\mathrm{GBL}=3 \quad \mathrm{ARA}=3 \mathrm{NUX}=4 \mathrm{NUY}=1 \quad \mathrm{NUZ}=1$

COM=!FINAL ARRAY!

FILL 87910 END FILL

END ARRAY

READ BNDS +XB=VACUUM -XB=VACUUM +YB=REFLECT -YB=REFLECT

$+\mathrm{ZB}=\mathrm{REFLECT}-\mathrm{ZB}=\mathrm{REFLECT}$

END BNDS

READ START NST $=1$ XSM=53.5 XSP=67.7 YSM=0 YSP=95.25 ZSM=0 ZSP=10

END START

READ PLOT

TTL=!X-Y SLICE!

PLT $=$ NO PIC $=$ MIXTURE

$X U L=-1 \quad Y U L=95.35 \quad Z U L=1 \quad X L R=113.6 \quad Y L R=-.1 \quad Z L R=1 \quad \cup A X=1 \quad \vee A X=0$

$W A X=0 \quad U D N=0 \quad V D N=-1$ WDN=0 NAX $=110 \quad N D N=49$ END

TTL $=$ !Y-Z SLICE!

PLT $=$ NO PIC $=$ MIXTURE $X U L=60.6$ YUL $=-.1 \quad Z U L=10.1$

$X L R=60.6$ YLR $=95.3$ ZLR $=-.1$ UAX $=0$ VAX $=1$

$W A X=0 \quad U D N=0$ VDN=0 WDN $=-1 \quad N A X=110 \quad N D N=49 \quad E N D$

END PLOT

END DATA

END

Note: As indicated on the SOLNUO2F2 line, the density of uranyl fluoride for this example was $800 \mathrm{gU} / \mathrm{l}$. This same input file was used for the calculations shown in Fig. D3, except that the density in the $\mathrm{PARA}(\mathrm{H} 2 \mathrm{O})$ line was varied between $10^{-6}$ and 1.0 
1 Martin Marietta Energy Systems (MMES) Nuclear Criticality Safety Software Control Plan K/ESH-3, December 18, 1991.

2 SCALE: A Modular Code System for Performing Standardized Computer Analyses for Licensing Evaluation, NUREG/CR-0200, Revision 4 (ORNL/NUREG/CSD-2/R4), Volumes I, II, and III,. April 1992. Available from Radiation Shielding Center as CCC545.

3 Lee, Billy L. Jr., Validation of Nuclear Criticality Software, KENO V.a., with the 27Group ENDF/B-IV Cross Sections, POEF-T-3636, Portsmouth Gaseous Diffusion Plant, Piketon, $\mathrm{OH}$ (to be published). 

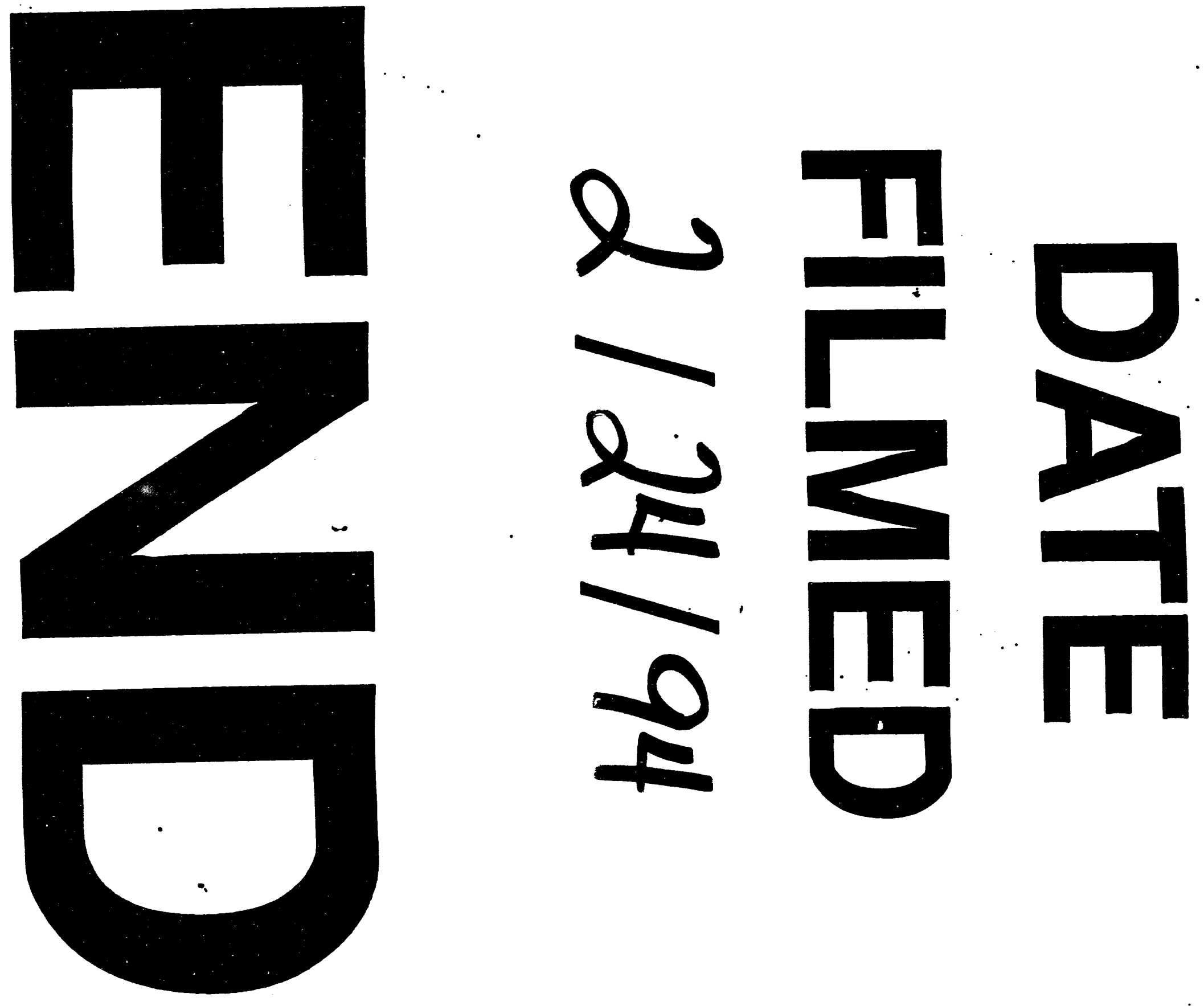
